\title{
AVIAN CHOLERA AMONG ARCTIC BREEDING COMMON EIDERS SOMATERIA MOLLISSIMA: TEMPORAL DYNAMICS AND THE ROLE OF HANDLING STRESS IN REPRODUCTION AND SURVIVAL
}

\author{
by \\ E. Isabel Buttler \\ M.Sc., Victoria
}

Thesis submitted to the

Faculty of Graduate Studies and Research

in partial fulfillment of the requirement for the degree of

\section{Master of Science}

Department of Biology

Carleton University

Ottawa, Ontario, Canada

(C) Isabel Buttler 2009 
Library and

Archives Canada

Published Heritage

Branch

395 Wellington Street

Ottawa ON K1A 0N4

Canada
Bibliothèque et

Archives Canada

Direction du

Patrimoine de l'édition

395 , rue Wellington

Ottawa ON K1A ON4

Canada
NOTICE:

The author has granted a nonexclusive license allowing Library and Archives Canada to reproduce, publish, archive, preserve, conserve, communicate to the public by telecommunication or on the Internet, loan, distribute and sell theses worldwide, for commercial or noncommercial purposes, in microform, paper, electronic and/or any other formats.

The author retains copyright ownership and moral rights in this thesis. Neither the thesis nor substantial extracts from it may be printed or otherwise reproduced without the author's permission.
Your file Votre référence ISBN: 978-0-494-52003-1 Our file Notre référence ISBN: 978-0-494-52003-1
In compliance with the Canadian

Privacy Act some supporting forms may have been removed from this thesis.

While these forms may be included in the document page count, their removal does not represent any loss of content from the thesis.
AVIS:

L'auteur a accordé une licence non exclusive permettant à la Bibliothèque et Archives Canada de reproduire, publier, archiver, sauvegarder, conserver, transmettre au public par télécommunication ou par l'Internet, prêter, distribuer et vendre des thèses partout dans le monde, à des fins commerciales ou autres, sur support microforme, papier, électronique et/ou autres formats.

L'auteur conserve la propriété du droit d'auteur et des droits moraux qui protège cette thèse. $\mathrm{Ni}$ la thèse ni des extraits substantiels de celle-ci ne doivent être imprimés ou autrement reproduits sans son autorisation.

\section{Canadä}




\begin{abstract}
Schedules of breeding activity and mortality of Common Eiders were monitored daily during annual avian cholera epidemics (2004-2008) at East Bay Island in northern Hudson Bay, Canada, to assess variation in disease dynamics within and among years. Dates of first mortalities and annual mortality were not related to host density, but total mortality increased with epidemic duration, peaking at over 30\% in 2006 and 2008. Risk of mortality increased throughout each season and rose most steeply in 2005 when only bacterial serotype 1 caused deaths, unlike in subsequent years when serotype $3 \times 4$ was present. Restraint duration did not prevent breeding, but delayed egg-laying and increased the probability of death in 2007, but not in 2008 when restraint duration was reduced. These findings suggest that exposure duration, bacterial serotype, and stressors which can enhance susceptibility should be considered important in understanding avian cholera outbreaks.
\end{abstract}




\section{ACKNOWLEDGEMENTS}

This study was supported by Environment Canada, Nunavut Wildlife Management Board, Seaduck Joint Venture, Canadian Network of Centres of Excellence ArcticNet, Natural Sciences and Engineering Research Council of Canada and the Department of Indian Affairs and Northern Canada. Logistical support was provided by the Polar Continental Shelf Project, and in Iqaluit by the Nunavut Research Institute and Environment Canada, particularly M. Mallory, J. Akearok, A. Fontaine. I thank the Hunters and Trappers Association and the Community of Coral Harbour for their continuing support. I am indebted to Guylaine Séguin, Stéphane Lair for performing necropsies and histopathology and David Blehert for the serotyping of bacterial isolates and to Catherine Soos for coordinating and securing the funds for laboratory analyses. Dr. Flemming Merkel from the National Environmental Research Institute, Denmark, and Dr. Jean-François Giroux, Professor of Biology at Université du Québec à Montréal graciously permitted the use of their talks presented at the $3^{\text {rd }}$ North American Sea Duck Conference. Thanks to Rhoda Ungalak from Igloolik, Theo Ikummaq, conservation officer, Igloolik, for conversations about Common Eider mortalities in the northern Foxe Basin region and Dominique Henri for information on eider mortality off Cape Dorset. Thank you to the field crews 2004-2008 for their good company and hard work: R. Kelly, E. Sénéchal, L. Berzins, R. Ludkin, J. Nakoolak, O. Love, M. Morrisette, B. Laliberté, J. Verhagen, D. Henri, C. Soos, J. Straka, J. Hiscock, L. Parker, L. Jolicoeur, H. Nyegaard, H. Jewel, L. Chirrey, V. Richards. Thanks also to earlier field crews for their contributions to the project. Thanks also to Myra Robertson and Maureen Kay for their iii 
often creative approach to making this project happen. I greatly appreciated the helpful comments on many drafts of Chapter 3 by Sébastien Descamps. Thanks to Paul Smith for statistical advice. And finally thank you to my supervisors Grant Gilchrist (Canadian Wildlife Service) and Mark Forbes (Carleton University) for their help and encouragement and thanks to Antoine Morin (committee member, University of Ottawa) for providing helpful comments whenever needed. 


\section{TABLE OF CONTENTS}

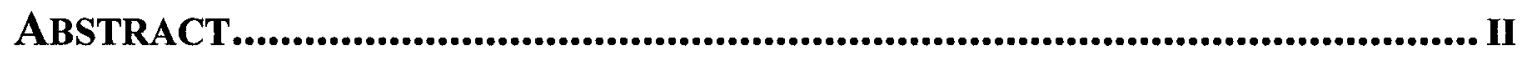

ACKNOWLEDGEMENTS.............................................................................. II

TABLE OF CONTENTS ................................................................................... V

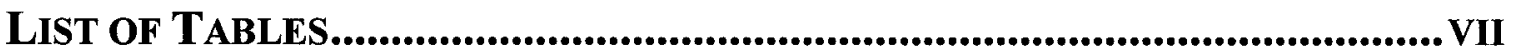

LIST OF FIGURES ........................................................................................... VIII

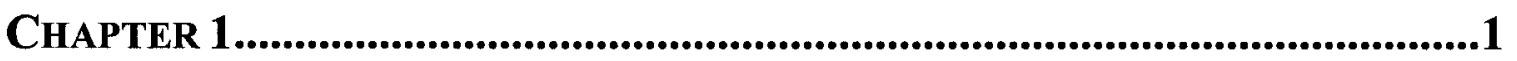

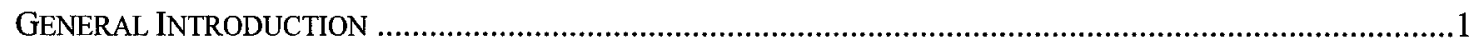

The bacterium Pasteurella multocida ….................................................................................... 6

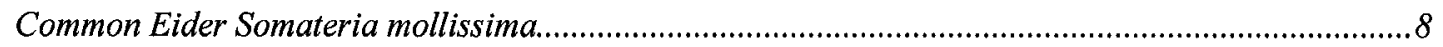

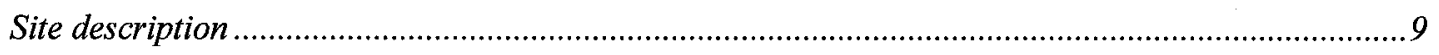

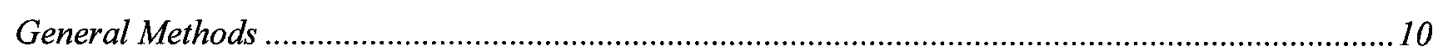

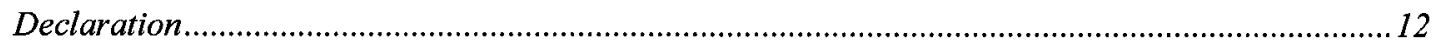

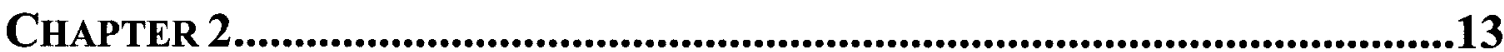

Temporal Dynamics of Avian Cholera Epizootics ObSERved AMONg COLONIALly Nesting

COMMON EIDERS SOMATERIA MOLLISSIMA IN ARCTIC CANADA ……......................................................

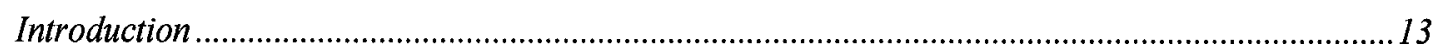

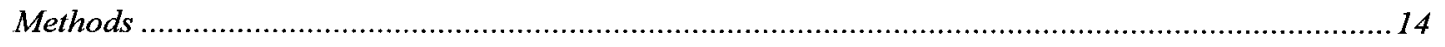

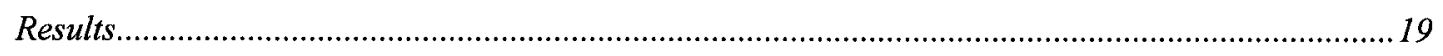

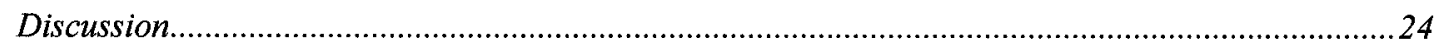

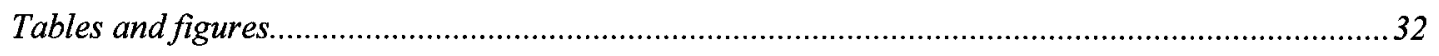

$\mathrm{V}$ 


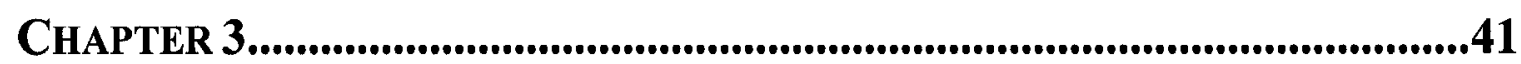

HANDLING STRESS LOWERS SURVIVAL AND DELAYS REPRODUCTION OF BREEDING FEMALE COMMON

EIDERS SOMATERIA MOLLISSIMA DURING AN AVIAN CHOLERA OUTBREAK ................................................. 41

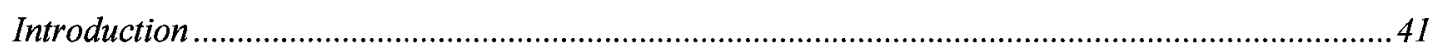

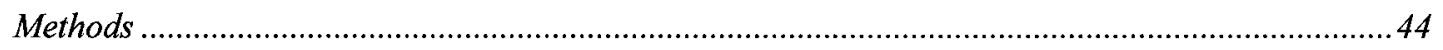

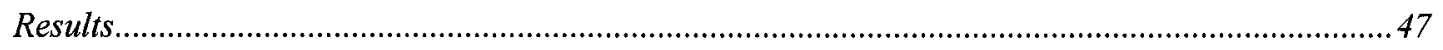

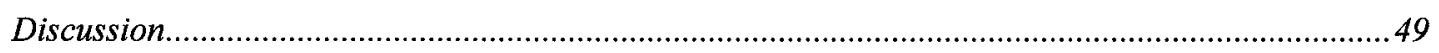

Figures

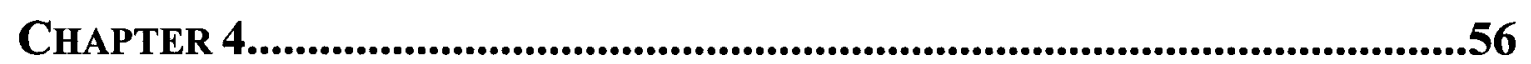

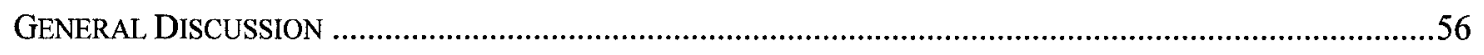

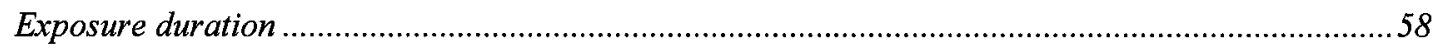

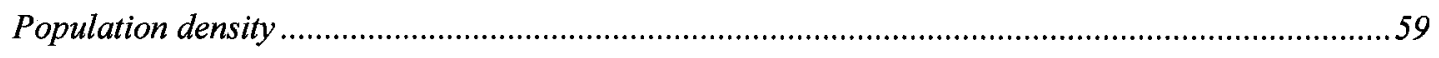

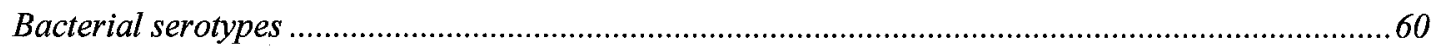

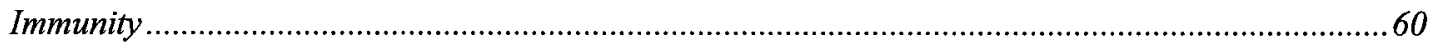

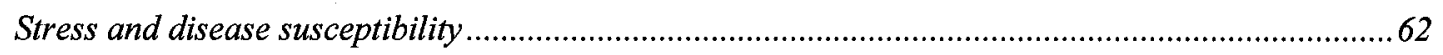

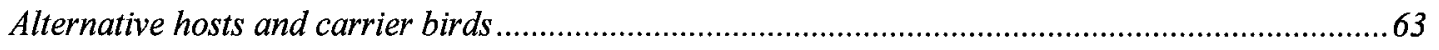

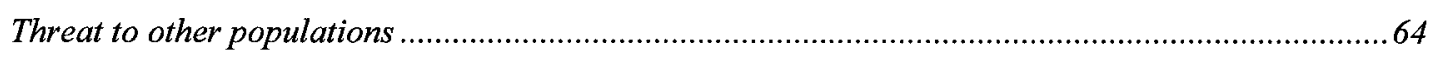

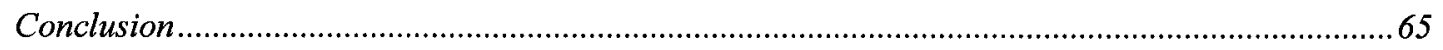

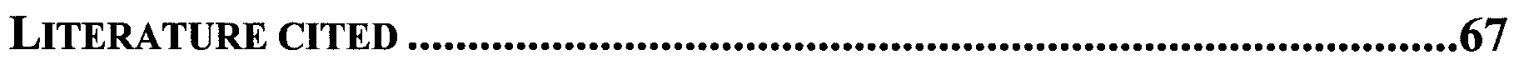

vi 


\section{LIST OF TABLES}

TABLE 1. PASTEURELLA MULTOCIDA SEROTYPES OF BACTERIAL ISOLATES OBTAINED FROM COMMON EIDER CARCASSES BETWEEN 2005 AND 2008.

vii 


\section{LIST OF FIGURES}

FIGURE 1. COLONY SIZE ESTIMATES AND NUMBER OF RECOVERED FEMALE CARCASSES 2000-2008_..............33

FIGURE 2. ANNUAL NESTING DENSITY AND PERCENT MORTALITY AMONG BREEDING FEMALES......................34

FIGURE 3. ANNUAL PERCENT MORTALITY AMONG BREEDING FEMALES AND EPIDEMIC DURATION.................35

FIGURE 4. PERCENT MORTALITY AMONG BREEDING FEMALES 2004-2008 ................................................

FIGURE 5. COLONY ATTENDANCE AND TIMING OF DISEASE ONSET 2004-2008 …........................................37

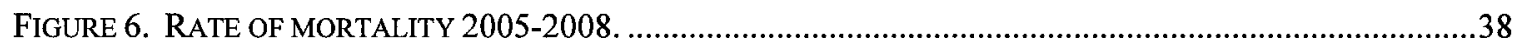

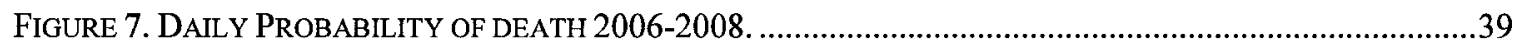

FIGURE 8. FREQUENCY DISTRIBUTION OF INDIVIDUAL MORTALITY RELATIVE TO INCUBATION STAGE AND DAY IN EPIDEMIC 2006-2008

FIGURE 9. RESTRAINT DURATION AND THE PROBABIILTY OF DEATH 2007 AND 2008 ...................................54

FIGURE 10. DELAY TO EGG-LAYING RELATIVE TO RESTRAINT DURATION 2007 AND 2008_.........................55

viii 


\section{CHAPTER 1}

\section{GENERAL INTRODUCTION}

Theoretical studies have suggested that pathogens might regulate host abundance (e.g. Anderson and May 1978). The potential importance of pathogenic bacteria in reducing host survival and reproduction and in affecting subsequent host population dynamics has since been recognized (Scott 1988, Dobson and Hudson 1995, McCallum and Dobson 1995, de Castro and Bolker 2005, Smith et al. 2006). However, empirical evidence on the regulation of host populations by pathogens is difficult to obtain (Dobson and Hudson 1995) and the role that pathogens play within wildlife populations in terms of temporal dynamics is only now being unraveled (Smith et al. 2009).

The impact a pathogen has on its host population depends on complex interactions between the host(s), pathogen, and the environment, which determine the rate of transmission of the pathogen to susceptible individuals. The rate of transmission is governed by the probability of an encounter between a susceptible individual and the pathogen, the probability that this encounter will result in a successful invasion by the pathogen, and the probability that the infection leads to the death of the host (Gulland 1995, Côté and Poulin 1995, Otto and Day 2007). The encounter rate between host and parasite may be regulated by host density (density dependence, Anderson and May 1979), density of infective individuals (frequency dependence; McCallum et al. 2001), a combination thereof (Ryder et al. 2007), pathogen density (Côté and Poulin 1995), host behaviour (Harwood and Hall 1990), and encounter duration. The probability that an encounter will lead to infection and/or death is governed by the virulence of the 
pathogen, and by factors such as stress (for review see McEwen et al. 1997) or life history stage (e.g. Bourgeon et al. 2006a) which can modulate the immune function of individuals. Some of these factors are important to certain pathogens, but not to others and investigations that are specific to isolated host-pathogen associations are warranted.

Theoretical models have shown that the impact of a pathogen on its host varies greatly depending on the factors determining the rate of transmission between individuals. For example, when transmission is density-dependent, i.e. encounter rate increases as inter-individual distance decreases, pathogens are unlikely to persist within a population below a critical population threshold (Anderson and May 1979, Lloyd-Smith et al. 2005). By contrast, such a threshold does not exist if transmission is dependent on the frequency of infectious individuals (Lloyd-Smith et al. 2005) or if both density and frequency are implicated in transmission (Ryder et al. 2007). If reduced to sufficiently low numbers, affected populations become vulnerable to extirpation due to other stochastic events even in the absence of further pathogen-induced mortality (Harwood and Hall 1990, Dye et al. 1995, de Castro and Bolker 2005).

Due to its detrimental effect on immune function (McEwen et al. 1997), stress is generally thought to contribute to the emergence of disease (e.g. Samuel et al. 2007), and stressors may be environmental and/or anthropogenic (Wingfield et al. 1998, Smith et al. 2009). Stress can trigger an emergency life history stage whereby animals suppress reproductive activity (Scott 1988, Wingfield et al. 1998). Delaying (e.g. Lepage et al. 2000) or skipping breeding results in decreased fecundity. To forgo breeding in the presence of disease mortality, can accelerate population declines by reducing the recruitment of new breeders into the population. 
Contagious pathogens have caused severe declines among their host populations (de Castro and Bolker 2005), but the magnitude of these declines depends on the characteristics of the individual host-pathogen association. For example, colonial species may be at high risk of infection irrespective of density since individuals necessarily come into close contact. Thus, encounter rate may increase with the number of infectious individuals (Harwood and Hall 1990). Encounter duration and/or group size may be particularly important in the presence of a non-motile pathogen which accumulates in the environment over time (Côté and Poulin 1995). Pathogens infecting more than one host are likely to cause severe population declines (Smith et al. 2009) irrespective of the factors influencing transmission rate (de Castro and Bolker 2005), since alternative hosts constitute a reservoir of the pathogen.

Infection and mortality of breeding individuals belonging to a population which is characterized by low annual reproduction rates and long life expectancy often kills individuals that are most valuable to the maintenance of the population. Unless survivors acquire permanent immunity or parasite induced mortality is compensated for by an increased reproductive output of uninfected individuals (Dobson and Hudson 1995), such populations are predicted to decline and to recover only slowly from epidemics.

Due to the multitude of factors influencing host-pathogen interactions in the wild and the difficulty in obtaining such data, studies that examine the impact of infectious diseases on wild populations are limited (Gulland 1995). Assessing the dynamics between pathogens and their hosts in the wild is additionally complicated as it is commonly impossible to reliably distinguish between susceptible, infected, and recovered but potentially contagious, individuals (Dobson and Hudson 1995). Observational studies 
of the progression of disease mortality within a season and comparisons of the disease dynamics between multiple epizootics may allow for inferences about the ecology of a pathogen and the nature of the governing host-pathogen interactions.

The bacterial disease known as avian cholera or Pasteurellosis is one of the most important diseases among North American waterfowl. It often causes mass mortality, primarily on the wintering and staging grounds but also among colonially nesting water birds (Wobeser 1997, Friend 1999). The disease was first described at the end of the $18^{\text {th }}$ century in France when it was observed in domestic poultry (Samuel et al. 2007). In North America, avian cholera was first detected in wild waterfowl in Texas in 1944 (Gordus 1993) and has since spread northward and eastward (Samuel et al. 2007).

Among the species affected by avian cholera in eastern North America are Common Eiders where the disease was first reported in 1963 on Common Eider $S . m$. dresseri colonies in Maine (Gershman et al. 1964). Avian cholera has since occurred periodically among nesting eider populations in Maine, the St. Lawrence River (Reed and Cousineau 1967, Jean-François Giroux, personal communication), and the Gulf of St. Lawrence (Goltz and Bowes 1994). Prior to 2004, avian cholera had not been reported among arctic nesting eiders (Goudie et al. 2000) and interviews with Inuit hunters suggest that mass mortalities in northern Hudson Strait and off Southampton Island have not been observed within their lifetime (Henri 2007). However, outbreaks elsewhere may have gone unidentified and unreported. The first confirmed avian cholera outbreaks among arctic nesting eiders occurred on colonies off the Ungava Peninsula (Gaston 2004, Kwan 2004) concurrent with the detection of several carcasses on the largest Common Eider colony in 
the eastern Canadian Arctic located in northern Hudson Bay, Nunavut, Canada, hereafter East Bay Island.

Between 2004 and 2008, avian cholera has been observed annually at East Bay Island. This system provides an ideal opportunity to closely observe the progression of the avian cholera epizootics within and between years. Observers have been present at the site throughout each breeding season (May - August) since 1996 prior to the appearance of avian cholera. In all years of avian cholera epizootics, the population appeared initially healthy with the disease first evident on the colony weeks after the arrival of the birds. Subsequently, the spread of the disease from 2004 onwards within the population as well as the within season disease dynamics could be closely monitored.

The objective of my study was to describe the annual and inter-annual temporal dynamics of the recurring avian cholera epizootics, in order to make inferences about the ecology of the disease and to test the importance of stress in disease mortality. Limiting my observations to females only, Chapter 2 is an exploration of possible associations between 1) host density and disease initiation and mortality, 2) between encounter duration and mortality. Chapter 2 also describes within season rates of mortality, assesses the impact of the disease on population size, and compares the epizootics among years. In Chapter 3, I examine the impact of handling stress on avian cholera mortality and reproductive choices among Common Eider females. In Chapter 4, I discuss the major findings and possible avenues for further research. 


\section{The BACTERIUM PASTEURELla MULTOCIDA}

Avian cholera, or fowl cholera is a highly contagious, naturally occurring disease. It is caused by the highly variable, facultative intracellular, generally capsular bacterium, Pasteurella multocida (Hundt and Ruffolo 2005). The bacterium is pathogenic to several species of mammals and over 190 species of birds (Samuel et al. 2007). Three subspecies have been identified (Harper et al. 2006) but, based on phenotypic differences of capsule antigens, five serogroups (A-F) can be distinguished. These serogroups are further classified into 16 serotypes (1-16) based on the molecular structure of the capsular liposaccharide antigens (Wobeser 1997, Harper et al. 2006). Different strains of $P$. multocida can bear capsular antigens characteristic of more than one serotype.

The presence, structure, and size of the capsule determines the virulence of the bacteria, particularly in serogroup A (Harper et al. 2006), the serogroup most commonly found in birds (Wobeser 1997). Modified acapsular strains are less virulent than their capsular counterparts (Harper et al. 2006), but can revert to their capsular form after repeated passage through mice (Rosen 1971). Both forms increase in virulence after repeated passage through live turkeys (Matsumoto and Strain 1993). Contrary to this observation, virulence of the bacteria seemed to diminish towards the end of some avian cholera outbreaks as an increasing number of apparently sick birds was observed while generally, early during an outbreak, the disease kills without any obvious symptoms (Rosen 1971, Botzler 1991).

It is generally believed that $P$. multocida invades the host through the respiratory tract (Wobeser 1997, Harper et al. 2006); possibly through the inhalation of bacterialaden water aerosols (Rosen 1969, Blanchard and Syzdek 1970), ingestion of 
contaminated water, and bird-to-bird contact (Botzler 1991, Wobeser 1997, see also Samuel et al. 2003a). The ability to adhere to mucous membranes is enhanced by the presence of fimbriae, which have been found in some serotypes of the serogroup A (Harper et al. 2006).

In waterfowl, avian cholera is usually thought to be a peracute disease (Wobeser 1997) that often kills its host within 12 to 36 hours (Botzler 1991, Samuel et al. 2003a). Death may be accompanied by violent muscle spasms or general lethargy. It is thought to be caused by endotoxic shock due to autolysis of a large number of bacteria released from ruptured liver and spleen phagocytes (Samuel et al. 2003a, Harper et al. 2006). Accordingly, bacteria are only detectible in the blood shortly before death, but their high numbers suggest a bacterial generation time of only 15 to 20 minutes (Frost and Adler 2000).

Virulent bacteria are thought to enter the environment when bacteria laden nasal discharge or intestinal contents are released from sick, recently dead, and/or partially scavenged birds (Rosen 1971, Botzler 1991, Wobeser 1997). Virulent bacteria have been isolated from water samples taken during avian cholera epizootics (e.g. Price and Brand 1984, Samuel et al. 2003b). Under natural conditions, bacteria may remain viable from days to weeks after release into the environment (Price and Brand 1984, Botzler 1991). However, the environment is not likely to act as an inter-annual reservoir of the bacteria (Samuel et al. 2004, Blanchong et al. 2006b). Instead, the disease is thought to be maintained in a population by apparently healthy carriers of virulent bacteria (Samuel $e t$ al. 1997, 2005, 2007). Indeed, pathogenic P. multocida have been isolated from 
apparently healthy wild birds which are thought to shed virulent bacteria orally or in their feces (Samuel et al. 1997, 2003a, 2005).

Immunity to the bacteria is thought to chiefly involve the humoral immune system through the production of antigens since, in the presence of a capsule, $P$. multocida seem to be able to evade their hosts' innate immune defense (i.e. phagocytosis and bactericidal properties of the blood serum, Harper et al. 2006). However, it remains unclear whether permanent immunity to the disease can be acquired (Samuel et al. 2007, but see Boyce $e t$ al. 2004). Chronic infections, with symptoms such as localized inflammation and swelling of the leg and wing joints, are known to occur in domestic poultry (Rimler and Glisson 1997, cited in Blackall and Miflin 2000). Similar symptons have not been reported in wild birds.

\section{COMMON EIDER SOMATERIA MOLLISSIMA}

Common Eiders Somateria mollissima are gregarious, long-lived sea ducks with relatively low annual reproductive success (Goudie et al. 2000). They generally nest in colonies and migrate some distance to wintering areas where they are often found in dense aggregations particularly at high latitudes (e.g. Gilchrist and Robertson 2000). Females are highly philopatric with $70 \%$ to $100 \%$ returning to their natal colony to breed (Wakeley and Mendall 1976, Goudie et al. 2000). Males, in contrast, disperse and follow females to their breeding colonies. (e.g. Swennen 1990). Once incubation has started, males leave the colony to molt. Only the females incubate, laying on average three to four eggs in the Canadian Arctic (Robertson et al. 2001). During the 23 to 30 day incubation period, females fast, and therefore, breeding success is partly dependent on 
energetic reserves accumulated prior to nesting (e.g. Parker and Holm 1990, Criscuolo et al. 2000, Bottitta 2001). During incubation, females lose up to $45 \%$ of their initial body mass (Goudie et al. 2000) and may experience a decrease in immune function (e.g. Hanssen et al. 2005, 2006, Bourgeon and Raclot 2006). If in poor body condition prior to laying, females may skip a breeding year entirely (Hanssen et al. 2003b, see also Swennen 1990). Annual duckling survival can be poor (Goudie et al. 2000) but, in the absence of additive sources of mortality such as hunting or disease, this is off-set by a relatively high annual adult survival rate of over $80 \%$ (Goudie et al. 2000).

Common Eiders are frequently harvested at their wintering grounds (Goudie et al. 2000, Merkel 2004b) and an intense commercial harvest of eiders wintering in Greenland in particular, was considered unsustainable (Merkel 2004a, Gilliland et al. 2009). In 2001, the Greenland hunting season was subsequently shortened leading to a marked increase in Common Eider breeding populations in Greenland and Canada (Flemming Merkel, personal communication).

\section{SITE DESCRIPTION}

The study was conducted on East Bay Island, a 24-ha island located within the East Bay Migratory Bird Sanctuary, Southampton Island, Nunavut, Canada $\left(64^{\circ} 01^{\prime} \mathrm{N}, 81^{\circ} 47^{\prime} \mathrm{W}\right)$. East Bay Island supports over 4000 nesting pairs annually ( $>170$ nests/ha) from populations wintering in southwest Greenland, in Atlantic Canada off the coast of Newfoundland and within the St. Lawrence estuary (S. m. borealis, Mosbech et al. 2006) and, to a lesser extent, in Hudson Bay Canada (S. m. sedentaria). In 1996, the Canadian Wildlife Service initiated a capture-mark-recapture program to monitor the East Bay 
Island eider population over the long term. Researchers have been present throughout each breeding season (June to August) since 1996 to study eider duck breeding ecology and survival. Eight observation blinds, accessible through above-ground canvas tunnels, are strategically placed on the island to maximize the observable area and to eliminate disturbance to the colony. Observations of breeding hens is facilitated by the island's small size (400mx800m), low topography (max. elevation: 9m a.s.1.), low tundra vegetation $(4-<8 \mathrm{~cm})$ and the presence of permanent freshwater ponds. The latter provide drinking water which eliminate the need for incubating females to leave the island, as they often do elsewhere (e.g. Criscuolo et al. 2000).

East Bay Island serves as a stop-over site for several migratory bird species during their northward migration, including waterfowl such as Lesser Snow Geese Chen caerulescens, Ross's Geese C. rossii, Canada Geese Branta canadensis, Brant Geese B. bernicla, and Northern Pintails Anas acuta and supports nesting populations of Canada Geese, Brant Geese, King Eiders S. spectabilis, Black Guillemots Cepphus grylle, Herring Gulls Larus argentatus and Snow Buntings Plectophenax nivalis.

\section{GENERAL METHODS}

Data collection for this thesis occurred throughout the breeding seasons (June-August) 2004 to 2008. Each year, Common Eiders were captured in $6 \mathrm{~m} \times 100 \mathrm{~m}$ flight nets (\#16 salmon gill nets, $14 \mathrm{~cm}$ mesh size) as they flew over the island during the pre-laying and early laying-periods. All birds were banded with one USGS metal band and two coloured alphanumeric Darvic bands (Pro-Touch, Saskatoon, Canada). All hens were additionally adorned with a unique colour and shape combination of two temporary plastic nasal 
markers (Juno Inc., Minneapolis, USA). Thus, individual hens could be subsequently identified and monitored while on nests. Nasal markers were attached with UVdegradable surgical monofilament ensuring the loss of the markers before fall migration.

Throughout each nesting season, seven observation blinds were visited twice daily by five observers (up to 30 person hours/day). During each visit, the nesting activity within five permanent plots, representing $7.9 \%$ of the nesting area of the island, was monitored to provide baseline nesting information. In addition, the colony was scanned with spotting scopes $(20 \mathrm{x}$ to $60 \mathrm{x})$ to monitor the progression of the avian cholera die-offs, and the breeding activity and the fate of nasal-tagged hens that often nested outside of permanent plots.

Any nasal-tagged hen was classified as a breeder when she was seen sitting on the same nest cup twice within a 36-hour period or was seen rushing back to a visually obscured nesting site after a drink break or disturbance on the colony. Her nesting status and fate were subsequently checked twice daily until hatch or nest failure. Specific dates of death are considered to be known for hens that died on their nests, were found within 24 hours of abandoning their nests, or were seen dead and yet untouched by scavenging Herring Gulls.

Throughout, nesting season is defined as the time between the detection of the first occupied nest and the fledging of the last brood monitored within the permanent nest monitoring plots. 


\section{DECLARATION}

A study like this involves many field assistants. I did not collect all the data, or even most of it, but was involved in study design, data collection, and collation for all aspects of this study. Additionally, I am responsible for choosing questions, analyzing the data, and for drawing inferences. In that vein, the work is largely mine, although I have relied on my co-supervisors for guidance. With respect to results based on laboratory diagnosis reported in this thesis, I note that each year, entire and partial carcasses were frozen to $-20^{\circ} \mathrm{C}$ within 24 hours of death and shipped to the Canadian Cooperative Wildlife Health Centre, St. Hyacinthe, QC, Canada, for necropsy and bacterial isolation (2005: $\mathrm{n}=12$

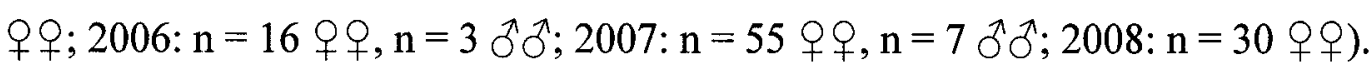
Identification of bacterial isolates was performed at the USGS - National Wildlife Health Center, Madison, WI, USA. Avian cholera was confirmed each year as the causative agent of the observed die-offs, thus excluding the possibility of lethal capture myopathy, an acute degeneration of muscle due to lactic acid buildup, as the cause of death (Dabbert and Powel 1993, Cox and Afton 1998, Ponjoan et al. 2006). Further, capture myopathy has never been detected during the East Bay Island banding program. At the time of printing, identification to serotype of bacterial isolates obtained from carcasses in 2008 was still pending. 


\section{CHAPTER 2}

\section{Temporal Dynamics of AVIan Cholera EPIZOotics ObSERVEd Among Colonially Nesting CoMmon Eiders Somateria mollissima IN ARCTIC CANADA}

\section{INTRODUCTION}

Although avian cholera has been reported among wild birds worldwide (e.g. Leotta et al. 2006, Weimerskirch 2004, Waller and Underhill 2007, Christensen 2008), it has been difficult to understand the ecology of the disease (Blanchong et al. 2006a). Specifically, the dynamics of the disease within breeding populations remain poorly described since avian cholera outbreaks have been primarily studied on the wintering grounds of waterfowl, where many species and subpopulations aggregate and where movement between wetlands is high (e.g. Blanchong et al. 2006a). Where studies have been conducted on breeding colonies, outbreaks were either managed to minimize further mortalities and/or within and between year patterns of mortality were not reported (e.g. Weimerskirch 2004, Waller and Underhill 2007). Yet, particularly observations of disease dynamics within a distinct breeding population may provide insights into the ecology and affects of avian cholera.

The avian cholera outbreaks recurring among Common Eiders at the East Bay Island breeding colony in Nunavut, Canada, provided the unique opportunity to compare temporal patterns of disease progression among seasons and to monitor the annual and inter-annual dynamics of the disease in the absence of management strategies aimed at reducing mortality. Females are highly philopatric to their natal site (for review see 
Goudie et al. 2000), emigration is rare (Wakeley and Mendall 1976, Swennen 1990), and incubating females do not leave the colony until the fledging of their young. Thus, previously exposed females are likely to return to the colony. In addition, each year, the birds arrive at their breeding grounds apparently healthy with the disease spreading on the colony weeks after their arrival. Therefore, rates of mortality can be monitored from the start of each epizootic. Here, I am presenting the annual and inter-annual dynamics of avian cholera epizootics observed each year between 2004 and 2008 on the Common Eider colony at East Bay Island, northern Hudson Bay, Nunavut.

The progression of the disease throughout each breeding season (June to August) was monitored by recording daily mortality, both throughout the colony and among individually marked breeding females. Changes in colony size within and among seasons were also monitored and total mortality was enumerated by conducting surveys of the entire colony after nesting. I examined how variation in host density and exposure duration influenced the timing and magnitude of the epizootics each year. By adopting an exploratory approach, I am hoping to enhance the understanding of the disease and to promote the formulation of testable hypotheses.

\section{METHODS}

\section{General}

Observations of eider duck nesting activity were made following the protocol outlined in General Methods (p. 10).

All analyses were performed using SPSS 15.0 (SPSS Inc., Chicago, IL). For general linear models, homogeneity of variances was assessed with Levene's tests. Normality of 
the data and GLM residuals was evaluated using Shapiro-Wilk tests. Mean values are given as means \pm standard errors (SE). Results were considered significant at $\mathrm{P}<0.05$ and all tests were two-tailed.

\section{Colony size}

To estimate colony size, I obtained the number of active nests $/ \mathrm{m}^{2}$ that were monitored within all permanent nest monitoring plots and multiplied this number by the total suitable nesting habitat available (19.44 ha). This estimate constitutes a minimum estimate of the true number of nesting pairs present as nest cups may be occupied by more than one nesting pair over the course of one nesting season, i.e. nest cups abandoned early in the season are sometimes reoccupied by another female. As the area of available nesting habitat on the island remained constant over the years, colony size is used as an index of nesting density.

\section{Total mortality}

I surveyed the entire island for dead birds after the departure of $>99 \%$ of the nesting hens.

During the surveys, five to seven observers walked abreast along flagged parallel line transects. Each person enumerated all dead hens, and recorded all other carcasses by species and sex between themselves and the adjacent observer. This process was repeated until the entire island was covered. Note that collected carcasses retrieved prior to the survey were included in the total number of mortalities. 


\section{Percent mortality}

I determined the percent mortality among breeding females using the nasal-tagged hens as a sample representative of the population (see General Methods, p. 10). Any nasaltagged hen was classified as a breeder when she was seen sitting on the same nest cup twice within a 36-hour period or was seen "rushing" back to a visually obscured nesting site after a drink break or disturbance on the colony. Scans conducted twice daily maximized the likelihood of detecting any dying or recently dead nasal-tagged hens and minimized the likelihood of the loss of carcasses to scavenging polar bears Ursus maritimus before detection. I calculated $\%$ mortality using $95 \%$ confidence intervals for binomial populations (Zar 1999).

\section{Disease dynamics}

\section{Colony attendance}

An index of bird density on the colony at the time of the first observed avian cholera mortalities was obtained by counting the number of active nests and the number of males within each nest monitoring plot twice daily. I considered a nest to be active once a hen had been seen sitting on the same nest cup three times during a 36-hour period. Only clearly visible nests were included in this analysis.

\section{Disease chronology}

The timing and initial rate of mortality increase was monitored by recording all fresh carcasses twice daily. Carcasses were considered to be fresh if they were intact, were 
being opened by feeding Herring Gulls, and/or were in rigor mortis which is clearly evident when carcasses are moved by feeding gull.

\section{Rate of mortality}

To obtain a measure of the rate of increase in mortality and to evaluate how this rate may vary between the years, I constructed a general linear model (GLM, $n=13)$ using an index of mortality (no. of fresh carcasses / live birds in permanent plots) as the response variable. I accounted for variation in the timing of the disease between years by applying a relative measure of time as predictor variable, i.e. number of days since first observed death (day of epizootic). Quadratic patterns were investigated by adding 'day of epizootic $^{2}$, to the model. I allowed for variation in the pattern among years by adding 'year' as a fixed factor and the interaction effects between 'year' and 'day of epizootic' or 'day of epizootic ${ }^{2}$. Variables were retained if they were significant at alpha $=0.05$.

Only the first 13 days of each epizootic were considered because carcasses could not be reliably classified as fresh and having died that day as the epizootic progressed and the number of scavenging gulls, attracted by the corpses, increased dramatically.

\section{Risk of mortality}

To determine whether the risk of mortality changed within each season throughout the epizootics of 2006 to 2008, I used Kaplan-Meier survival analysis to calculate the daily probability of death among nesting nasal-tagged hens (1-survival probability). This analysis allows for censored cases, i.e. cases/hens for which no death was observed during the season. The day on which the first mortality was observed on the island was considered the start of the epizootic and the days that lapsed between the start of the 
epizootic to death, nest abandonment, or hatch of each nasal-tagged hen was the time variable. The occurrence of a death was the modelled event. Death dates were considered to be known for nasal-tagged hens that were seen dead on the nest or were sighted dead elsewhere within 24 hours since their last presence on their nests. Hens found dead more than 24 hours after nest abandonment and hens with uncertain incubation start dates were excluded from the analysis. The date of death to within one day or less was known for 13 of 59 (2006), 12 of 81 (2007) and 9 of 50 (2008) nesting nasal-tagged hens with known incubation starts ( \pm 2 days). Only hens sitting on nests that were clearly visible during the epizootic were considered. Sample size for 2005 was too small and was excluded from the analysis. Differences between years were assessed using the Mantel-Cox $\mathrm{Chi}^{2}$ test.

I performed Pearson's correlation analyses to investigate the relationships between the day of the epizootic on which a hen died and her incubation stage at death (proxy for immune status) and the number of days she sat on the nest during the epizootic prior to death (proxy for exposure duration) in order to detect possible confounding effects of these variables. I did this because the probability of encountering the pathogen is likely to increase as the epizootic progresses and immune function declines as incubation progresses (Bourgeon et al. 2006a). Both the mean incubation stage at death and the number of days hens with known death dates were on their nests during the epizootic, did not differ among the years (incubation stage at death: $F_{2,31}=0.277, P=0.760, n=34$; means: $2006=18.0 \pm 1.874, \mathrm{n}=13 ; 2007=16.67 \pm 17.20, \mathrm{n}=12 ; 2008=18.56 \pm 1.717$, $\mathrm{n}=9$; number of days on nest in epizootic: $F_{2,31}=0.301, P=0.742 ; n=34$; means: 2006 $=16.7 \pm 1.865, \mathrm{n}=13 ; 2007=14.3 \pm 1.750, \mathrm{n}=12 ; 2008=16.1 \pm 1.409, \mathrm{n}=9)$. Thus, data across years were pooled for subsequent analyses. Data were also normally 
distributed (incubation stage at death: $\mathrm{W}_{34}=0.951, \mathrm{P}=0.129$; days on nest in epizootic: $\mathrm{W}_{34}=0.971, \mathrm{P}=0.489$; day of epizootic: $\left.\mathrm{W}_{34}=0.981, \mathrm{P}=0.798\right)$.

\section{Avian cholera diagnosis}

Diagnostic tests were as described in the Declaration (see pg. 11).

No carcasses were collected for necropsy in 2004 and thus, the cause of death of these first 19 hens could not be subsequently confirmed. However, I consider 2004 to be the first year of the annual avian cholera outbreaks observed among Common Eiders on East Bay Island as no deaths had been observed on the island between 1996 and 2003 and since, concurrent with the first detection of several dead Common Eider hens on East Bay Island, avian cholera was confirmed as the cause of death of Common Eider carcasses discovered on colonies off the Ungava Peninsula in that year (Gaston 2004, Kwan 2004). These colonies are located on the migratory route of East Bay Eiders wintering in Atlantic Canada (Mosbech et al. 2006).

\section{RESULTS}

\section{Colony size and female mortality}

Between 2000 and 2004, the East Bay Island colony increased in size by an average of 16.9\% per year from an estimated 3323 to 5856 pairs (Figure 1). In 2004, I observed the first unusual mortalities on East Bay Island since $1996(n=19)$ which represented approximately $0.03 \%$ of all females breeding in that year. All deaths occurred at the end of the nesting season. 
Colony size did not influence the severity of the epizootic (Figure 2); instead, overall mortality among female breeders was associated with the duration the disease was present on the island in the presence of nesting hens (Figure 3). Percent mortality among breeding females increased six-fold from 5.3\% in 2005 with 203 female carcasses being recovered to $32.7 \%$ in 2006 with 3200 female carcasses being recovered (Figure 4). Colony size increased only by $3 \%$ from 8367 (2005) to 8596 pairs (2006) during the same time period. The high mortality in 2006 likely resulted in the $28 \%$ decline in colony size to approximately 6190 nesting pairs in 2007 . In 2007 , mortality among breeding females, however, declined more steeply than colony size, decreasing by $50 \%$ to $16.5 \%$ with only 781 female carcasses being recovered. Colony size continued to decline slightly in 2008 ( $n=5826$ nesting pairs) resulting in an overall decline of $32.2 \%$ since 2006. Yet, despite the diminished colony size in 2008 , mortality among breeding females was high again at $31.6 \%$ with 1454 female carcasses being recovered (Figure 1).

\section{Male mortality}

Male mortality was low in all years, but was detected in all years in which the first mortality was observed prior to male departure (2005: 4 days, $1 \AA ; 2006: 24$ days, $30 \AA \delta$ 2007: 24 days, 15 ठึં; 2008: 19 days, 16 ठో).

\section{Disease dynamics}

During the first three years, the timing of the first mortality relative to the breeding phenology of the eiders advanced progressively (Figure 5). In 2004 and 2005, the first mortality was observed 17 days and 9 days, respectively, after the number of Common Eiders on the colony peaked (Figure 5). In all subsequent years, the first mortality was 
observed before the number of birds on the colony reached their peak (2006: 5 days; 2007: 4 days; 2008: 9 days) and consistently between 6 to 8 days after the first nest initiation within the permanently monitored plots (Figure 5). The timing of the first mortality relative to the eiders' breeding phenology remained consistent even though nesting in 2007 started 9 and 8 calendar days later than in 2006 and 2008 respectively. In all years but 2006, when a Canada Goose was the first bird to die, Common Eiders were the first to succumb to the disease.

Timing of first mortality was not associated with the number/density of birds on the island (Figure 5). The total number of Common Eider pairs on the island at the time of the first mortality was estimated to be 7944 in 2006 ( $\sim 331$ hens/ha), 4863 in $2007(\sim 202$ hens/ha), and 2495 in 2008 ( 104 hens/ha). This constituted $73 \%, 75.6 \%$, and $39.6 \%$, respectively, of the maximum colony size within the respective years.

Mortality increased in a quadratic fashion within the first 13 days of the epizootic. Both 'day of epizootic' and 'day of epizootic ${ }^{2}$, significantly influenced the 'mortality index' (day of epizootic: $F_{1,43}=9.2, P=0.004$; day of epizootic ${ }^{2}: F_{1,43}=48.8, P<$ 0.0001; Figure 6). The main effect 'year' did not remain significant when I added the interaction between 'year' and 'day of epizootic' $\left(\mathrm{F}_{3,43}=12.1, \mathrm{P}<0.0001\right)$. Parameter estimates of the interaction effect suggest that mortality increased more steeply during the first 13 day of the epizootic in 2005 than in other years (Figure 6). The overall quadratic model explained $88.9 \%\left(\operatorname{adj} . \mathrm{R}^{2}\right)$ of the variation in the mortality index. 


\section{Risk of mortality}

The probability of death continued to increase non-linearly throughout each entire season as the epizootic advanced, and these increases were not different among the years 2006 to 2008 (Mantel-Cox $\chi_{2}^{2}=1.566, P=0.457 ;$ Figure 7). However, the day of the epizootic on which a hen died was highly correlated with exposure duration, i.e. number of days hens spent on their nests in the epizootic prior to death (Spearman's R $=0.761, \mathrm{P}=0.000, \mathrm{n}=$ 34). Similarly, the day of the epizootic on which a hen died was highly correlated with incubation stage at death (Spearman's $\mathrm{R}=0.564, \mathrm{P}=0.001, \mathrm{n}=34$ ). There was no visible pattern in the incubation stage at death and the total number of days hens spent on their nests during the epizootic (Figure 8). Both incubation stage at death and the total number of days on the nest during the epizootic prior to dying varied widely within years (range of incubation stage at death: $2006=5-26$ days; $2007=7-26$ days; $2008=12-$ 26 days; range of number of days on nest in epizootic at death: $2006=4-25$ days; 2007 $=4-22$ days; $2008=11-24$ days; Figure 8).

\section{Avian cholera diagnosis}

Avian cholera was confirmed as the causative agent of all observed die-offs between 2005 and 2008 at East Bay Island. No samples were taken for necropsy in 2004.

Pasteurella multocida were successfully isolated from 11 of 12 (2005, all 우우), 18 of 19 (2006, 15 우, $\left.3 \delta^{\widehat{\partial}}\right), 43$ of $63\left(2007,38\right.$ 우, $\left.5 \delta^{\lambda}\right)$ adult Common Eider carcasses and parts. No bacteria could be isolated from ducklings $(2007: \mathrm{n}=4)$.

The bacteria causing the epizootics shifted from serotype 1 in 2005 to serotype $3 \times 4$ in 2007. In 2006, both serotypes were present with serotype 1 being identified in $31.25 \%$ 
of all analyzed carcasses $(n=16$; Table 1$)$. Identification of bacterial isolates obtained from carcasses in 2008 is still underway.

In all years but 2007, intact carcasses were collected. In 2007, wings, partially scavenged, and intact carcasses were sent for analysis. In 2005 and 2006, avian cholera was also diagnosed as the cause of death among Herring Gulls $(2005: n=3 ; 2006: n=1)$, Brant Geese (2005: $\mathrm{n}=3,2006: \mathrm{n}=2)$, Canada Geese $(2006: \mathrm{n}=1)$, and Snow Buntings (2005: $\mathrm{n}=1$ ). Only $P$. multocida serotype 1 was isolated from these species. In 2007 , no bacteria could be isolated from any species other than Common Eiders (collected: King Eider wings, $n=1$; Brant Goose wings, $n=1$; Snow Bunting carcasses, $n=4$; Black Guillemot carcasses, $n=3$ ).

The ability to isolate bacteria depends on the state of the sample provided. Bacteria were isolated from $82.05 \%$ of intact carcasses, but from only $55.56 \%$ and $40 \%$ of partially scavenged carcasses and wing samples, respectively.

\section{Symptoms}

There was a shift in the dominant symptoms exhibited just prior to death coincident with the shift from $P$. multocida serotype 1 in 2005 to serotype $3 \times 4$ in 2007 (Table 1). In 2005, the majority of moribund individuals exhibited uncontrollable muscle spasms and lethargy was only rarely noted. The proportion of lethargic moribund birds appeared to increase in 2006 when both serotypes, 1 and 3x4, were present. In 2007, when only serotype $3 \times 4$ was isolated from carcasses, lethargy, with hens resting their bills and often their wings on the ground while sitting, was the primary symptom exhibited just prior to death. 
Other symptoms observed include coughing, gagging, and eruptive discharge of mucous from the bill. These latter three symptoms, however, were rare. Mucous discharge from the bill was detected among birds up to nine days prior to the first observed death in the respective years, but it could not be determined whether birds exhibiting these early symptoms survived or died in the ensuing epizootic. Deaths among males were less frequently observed. However, during years with avian cholera epizootics males were observed with uncharacteristically drooping wings suggesting that they were infected with avian cholera.

\section{DISCUSSION}

\section{Density and exposure duration}

The first mortalities of eiders at East Bay Island were observed in 2004 as the colony was expanding in numbers (i.e. as the nesting density had increased by $43 \%$ since 2000 ;

Figure 1). Population density may enhance transmission of a non-motile pathogen such as $P$. multocida as the rate of contact between individuals increases and/or as stress increases with both factors potentially increasing the susceptibility of individuals to disease (e.g. McCallum et al. 2001, see also Chapter 3). In addition, high density has been associated with increased severity of avian cholera outbreaks on the wintering grounds of waterfowl (Blanchong et al. 2006a, Samuel et al. 2007) and with high carcass counts among nesting Snow Geese (Samuel et al. 1999) suggesting that total mortality may increase with population density.

I found no correlation between population density and the overall mortality at East Bay Island during the four years of this study (Figure 2). Instead, the number of female 
eiders that died increased with the duration of the epizootic (Figure 3) and more eiders died the earlier avian cholera appeared at the colony. At East Bay Island, breeding females remain on the colony throughout incubation and leave their nest only every one to four days to drink (Bottitta 2001). While sitting on the nest, direct contact between birds is low. During their drink breaks, however, hens are likely to contract virulent bacteria shed by sick, and dying birds or scavenged carcasses into the water (Botzler 1991). Therefore, incubating hens may be more likely to encounter the bacteria the longer the epizootic lasts. This may explain the positive relationship observed between the death toll and the duration of the epizootic (Figure 3).

I have detected no relationship between the date avian cholera appeared each season and the population density at that time (Figure 1). In 2004 and 2005, first mortalities were observed weeks after the number of individuals on the island peaked (Figure 5). By contrast, first avian cholera mortalities occurred between seven and nine days after the initiation of the first nest monitored within plots in 2006 and 2008, respectively, irrespective of the number of birds on the island at the time. Density factors also seem to have been irrelevant in the avian cholera outbreak observed on an eider colony in Digges Sound in 2004 where avian cholera spread on an island that is believed to have declined by $80 \%$ since 1999 (Gaston 2004). Therefore, it is unlikely that an increase in population density was a driving factor in precipitating the observed epizootics within seasons.

\section{Onset of avian cholera in a nesting season}

During the first three years of the epizootics, 2004 to 2006, the first avian cholera deaths were detected progressively earlier in the nesting season each year (Figure 5). A similar 
pattern of advancing start dates of epizootics has also been observed among Common Eider colonies, S. m. dresseri, in the St. Lawrence River, Québec, Canada (Jean-François Giroux, personal communication), and among Lesser Snow Geese Chen caerulescens nesting on Banks Island, Northwest Territories (Samuel et al. 1999). An advancing pattern in the onset of disease between years would be expected if the rate of transmission increased during successive years. Factors that may contribute to an increased rate of transmission, particularly when infection is directly transmitted between hosts, include an increased number of susceptible and/or of infectious individuals (review in Begon et al. 2002). As the number of infectious individuals increases the probability that a susceptible individual encounters an infectious individual increases. Similarly, the probability of infection increases with the number of susceptible individuals (Begon et al. 2002).

There is some evidence that immature geese may be more susceptible to avian cholera than adults (Samuel et al. 2007). At East Bay Island, young breeders may have entered the population as the colony grew in response to the reduction in the annual eider harvest implemented in Greenland in 2001 (Figure 1). If young eiders are more susceptible to avian cholera than adult birds, the recent increase in population size may have allowed the disease to spread at East Bay due to an increased number of susceptible individuals on the colony.

It is unlikely however, that differential susceptibility among individuals is the main factor determining the maintenance of the disease within the East Bay Island population. After repeated avian cholera outbreaks, one would expect the number of susceptible individuals, and therefore mortality, to decline in subsequent years as the most 
susceptible individuals succumb to the disease and overall reproductive output declines with colony size. Such a trend has not yet been observed at East Bay Island (Figure 4). An increase in the number of carriers of the disease over the years may lead to a temporal advancement in the date of disease onset as has been observed at East Bay Island. Indeed, carriers of pathogenic $P$. multocida, have been detected among Snow Geese (Samuel et al. 1997, 2005). Since P. multocida is also thought to be transmitted through contaminated water (e.g. Botzler 1991, Wobeser 1997), an increase in the number of carriers would result in a higher likelihood of several freshwater ponds becoming contaminated, thus increasing probability of exposure. Therefore, it is possible that the progressively earlier start dates of the epizootics observed annually are, in part, the result of an increasing number of infected but surviving carrier birds present on the island at the onset of the nesting season.

\section{Within season rate of mortality}

The probability that eiders died increased with the time elapsed since the first mortality was observed on the island (Figure 6). This result contradicts earlier impressions of decreasing virulence of the bacteria over time (Botzler 1991), but may support findings of Matsumoto and Strain (1993) who found that $P$. multocida that passed through their host several times increased in virulence. Alternatively, the bacterial concentration per encounter may increase as the epizootic advances and an increasing number of carcasses are scavenged. This is known to release large numbers of virulent bacteria into the environment (Botzler 1991, Wobeser 1997, Rosen 1971) where they can survive up to 113 days in soil and 30 days in water (Samuel et al. 2007). 
Behavioural or physiological changes over the course of incubation may contribute to the increased probability of dying late in the epizootic. For example, hens that died later in the epizootic also spent more days on their nest in the presence of the disease and died later in incubation than hens that died earlier in the epizootic, As incubation advances, incubating females leave their nests more often to drink from nearby ponds (Bottitta 2001). Thus, they may increase the likelihood of an encounter with the bacteria. At the same time, the risk of infection may increase over time as eiders experience a suppression of immune function as incubation progresses (Bourgeon et al. 2006a). However, between 2006 and 2008, there was no evidence that hens in the late stages of incubation were more likely to die than hens early in incubation. Instead, hens died at all stages of incubation (Figure 8). It is possible that variation in individual quality (Hanssen et al. 2003a, 2003b) and perhaps variable costs incurred during incubation (e.g. Hanssen et al. 2005, see also Descamps et al. 2009) could account for this observed lack of a relationship between incubation stage and mortality. I was unable to control for the role of individual variability in contributing to the increasing rate of mortality within seasons. Similarly, it was not possible to control for the effects of increasing bacterial virulence and density, encounter rate, risk of infection, and immunosuppression with the progression of the epizootics and the breeding season. The contribution of these factors to the increased risk of infection with the progression of the disease will require further investigation. 


\section{Serotype of $P$. multocida}

Between 2005 and 2007, the bacterial serotype causing mortality among the birds nesting on East Bay Island shifted from serotype 1 in 2005 to serotype $3 \times 4$ in 2007 . Both serotypes were isolated from carcasses in 2006 (Table 1). During the same time period, a shift in the predominant symptoms exhibited by moribund individuals was observed. While muscle spasms and convulsions predominated in 2005, dying hens exhibited lethargy in 2007 . In addition, the initial increase in the rate of mortality was steeper in 2005 than in any other year (Figure 6). This result may be influenced by the timing of the disease onset in 2005. In this year, avian cholera appeared on East Bay Island when hens were late in incubation. Therefore, the disease may have found the nesting hens in an immunocompromised state (Bourgeon et al. 2006a) leading to the relatively high rate in mortality in 2005 .

The rate of host mortality can also indicate pathogenic virulence (de Castro and Bolker 2004). Therefore, the higher rate of mortality observed in 2005 when compared to 2006 (both serotypes present) and to subsequent years (serotype $3 \times 4$ only) may indicate that $P$. multocida, serotype 1 , may be more virulent to eiders than serotype $3 \times 4$. Pathogens that exhibit high virulence are less likely to persist in a population since they kill their hosts quickly, thereby reducing the likelihood of host-to-host transmission and the survival of carrier hosts (Ganusov and Antia 2003, Ryder et al. 2007). At East Bay, $P$. multocida serotype 1 was isolated from carcasses in 2005 and 2006, but not in 2007. Similarly short cycles of avian cholera epizootics caused by serotype 1 have been observed on the St. Lawrence eider colonies (J.-F. Giroux, personal communication) suggesting that this strain is perhaps the more virulent among common eiders. 


\section{Future of the Common Eider population}

In the absence of disease mortality on the breeding grounds, survival among breeding adult females at the East Bay Island colony is high, averaging $85 \%$ (Sébastien Descamps, unpublished data). Like other seabirds, Common Eiders have deferred reproductive maturity, relatively low recruitment, and exhibit occasional non-breeding by adults (Coulson 1983, Goudie et al. 2000). These factors make them vulnerable to population declines Indeed, repeated high mortality among breeders due to avian cholera has resulted in a 32\% decline in the East Bay Island colony size since 2006 (Figure 1).

Pathogens with alternative host species, within which the pathogen is relatively benign and persists as a source of infection, can lead to large declines and may threaten the persistence of the focal host species (McCallum and Dobson 1995, de Castro and Bolker 2005). Thus, if P. multocida is maintained within the Common Eider population by alternative host species stopping-over or nesting on the colony, the East Bay Island population may continue to suffer avian cholera epizootics and may continue to decline. If, on the other hand, P. multocida is maintained within the East Bay population solely by Common Eider carriers, avian cholera outbreaks may cease over time. Pathogens limited to one host species are predicted to fade out once a critically low population threshold is reached (e.g. Anderson and May 1979), as the number of new susceptible individuals entering the population dwindles due to reduced reproduction or protective immunity (Dye et al. 1995, Lloyd-Smith et al. 2005). Yet, empirical evidence for the existence of such thresholds is rare (Lloyd-Smith et al. 2005).

Acquired permanent immunity can lead to declines in disease mortality in the absence of immigration by susceptible individuals (Dye et al. 1995, Lloyd-Smith et al. 
2005), which is thought to be low among eider populations (e.g. Wakeley and Mendall 1976, Swennen 1990). However, it is unclear whether permanent protective immunity to P. multocida develops in birds surviving an avian cholera infection (Samuel et al. 2007, but see Boyce et al. 2004). In the presence of permanent immunity, one may expect declining death rates over the years in the presence of avian cholera, a trend that has not yet been observed within the East Bay Eider population over the last five years (Figure 4). To predict the future of this eider population, it is important to consider the potential presence of immunity among survivors of the disease, the potential that alternative avian hosts, stopping-over or nesting at East Bay Island, to act as a reservoir for P. multocida, and the role of carrier birds will require further investigation.

The observed spread of the disease among male Common Eiders at East Bay may, however, threaten nesting populations elsewhere in the arctic. Male Common Eiders are not philopatric to their natal and breeding sites but instead disperse (Swennen 1990, Goudie et al. 2000, Mosbech et al. 2006). Survivors of an infection may carry pathogenic bacteria elsewhere. Indeed, dead eiders have been recovered on colonies around Cape Dorset in 2008 (Dominique Henri, unpublished data) suggesting that the disease has begun to spread to new nesting colonies, emphasizing the importance of learning more about the ecology of avian cholera in the wild. 


\section{TABLES AND FIGURES}

Table 1. Pasteurella multocida serotypes of bacterial isolates obtained from Common Eider carcasses between 2005 and 2008. Serotype shifted from serotype 1 in 2005 to serotype $3 \times 4$ in 2007 . Note the presence of both serotypes in 2006. At the time of printing serotyping of 2008 bacterial isolates was still pending.

\begin{tabular}{|c|c|c|c|c|c|c|}
\hline \multirow[b]{2}{*}{ Year } & \multirow[b]{2}{*}{ COEI } & \multicolumn{5}{|l|}{ Serotype } \\
\hline & & 1 & $3 \times 4$ & No growth & Not sampled & Total \\
\hline \multirow[t]{2}{*}{2005} & q & 11 & -- & 1 & -- & 12 \\
\hline & $\delta$ & -- & -- & -- & -- & 0 \\
\hline \multirow[t]{2}{*}{2006} & q & 5 & 10 & 1 & -- & 16 \\
\hline & $\delta$ & 2 & 1 & -- & -- & 3 \\
\hline \multirow[t]{2}{*}{2007} & q & -- & 38 & 14 & 3 & 55 \\
\hline & $\delta$ & -- & 5 & 2 & 1 & 8 \\
\hline \multirow[t]{2}{*}{2008} & q & pending & -- & -- & -- & 30 \\
\hline & $\delta$ & -- & -- & -- & -- & 0 \\
\hline
\end{tabular}




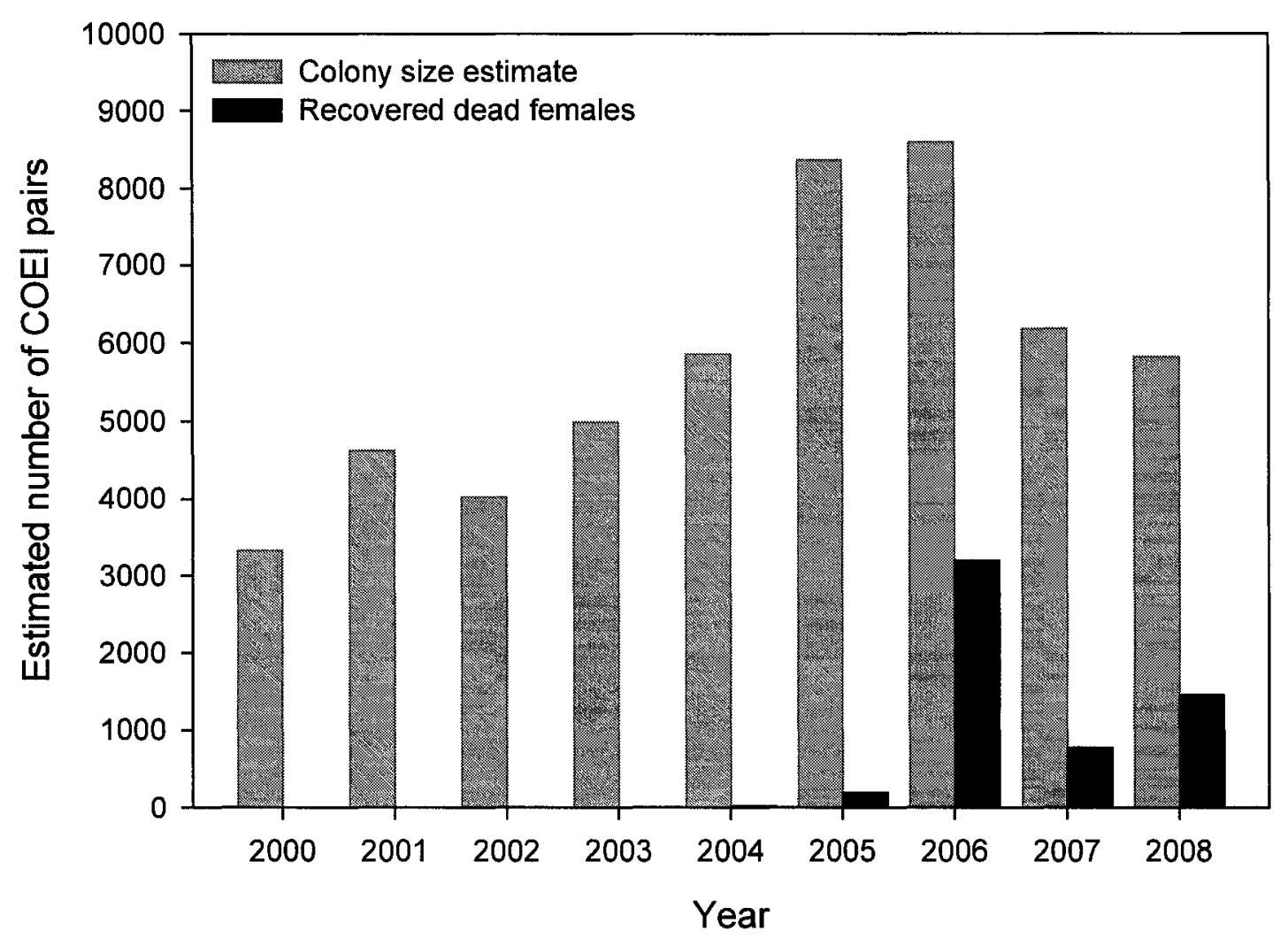

Figure 1. Colony size estimates between 2000 and 2008 and total number of female carcasses recovered. 


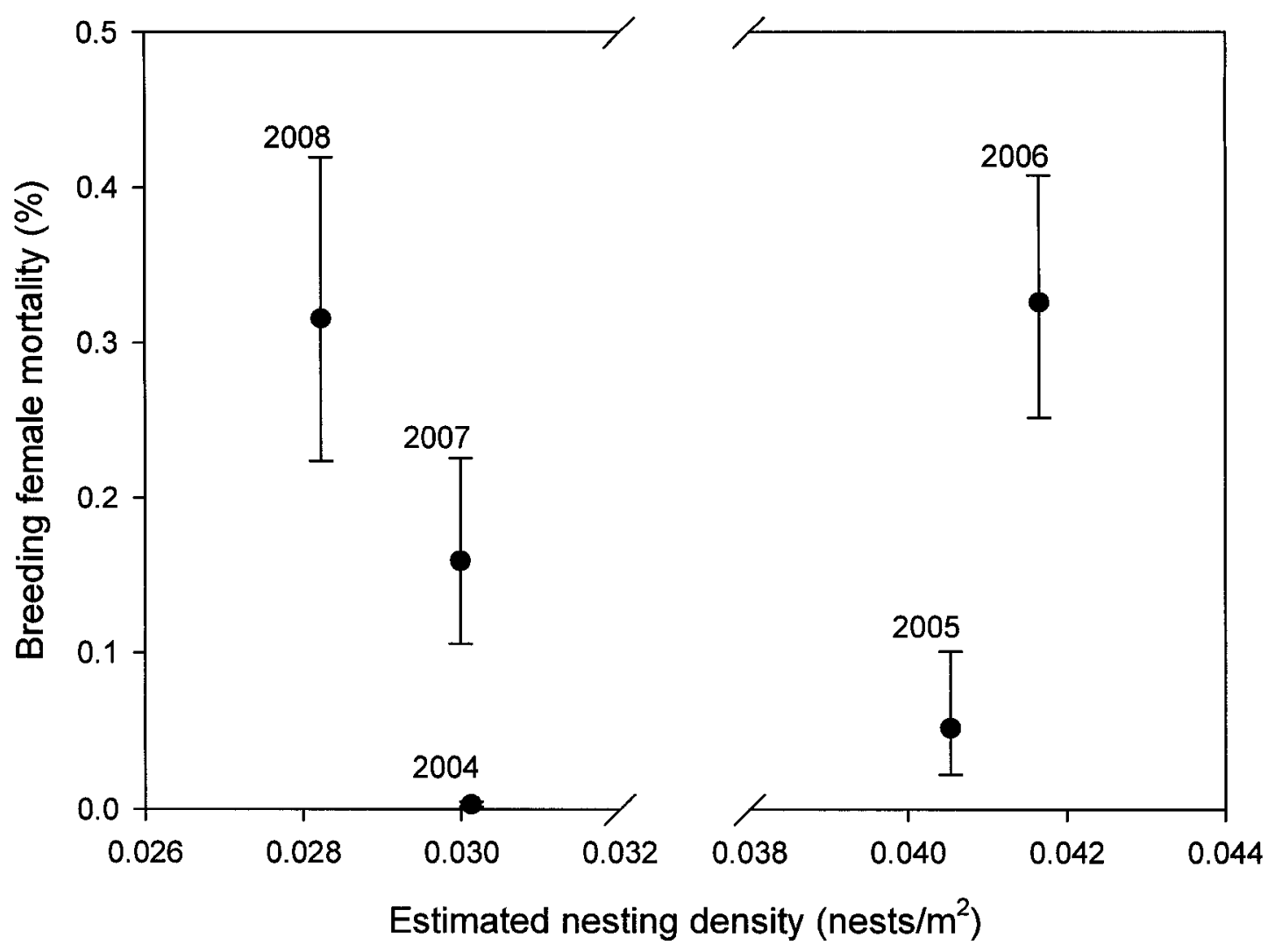

Figure 2. Annual estimated nesting density (nests $/ \mathrm{m}^{2}$ ) and percent mortality among breeding females. Error bars represent $95 \% \mathrm{CI}$. 


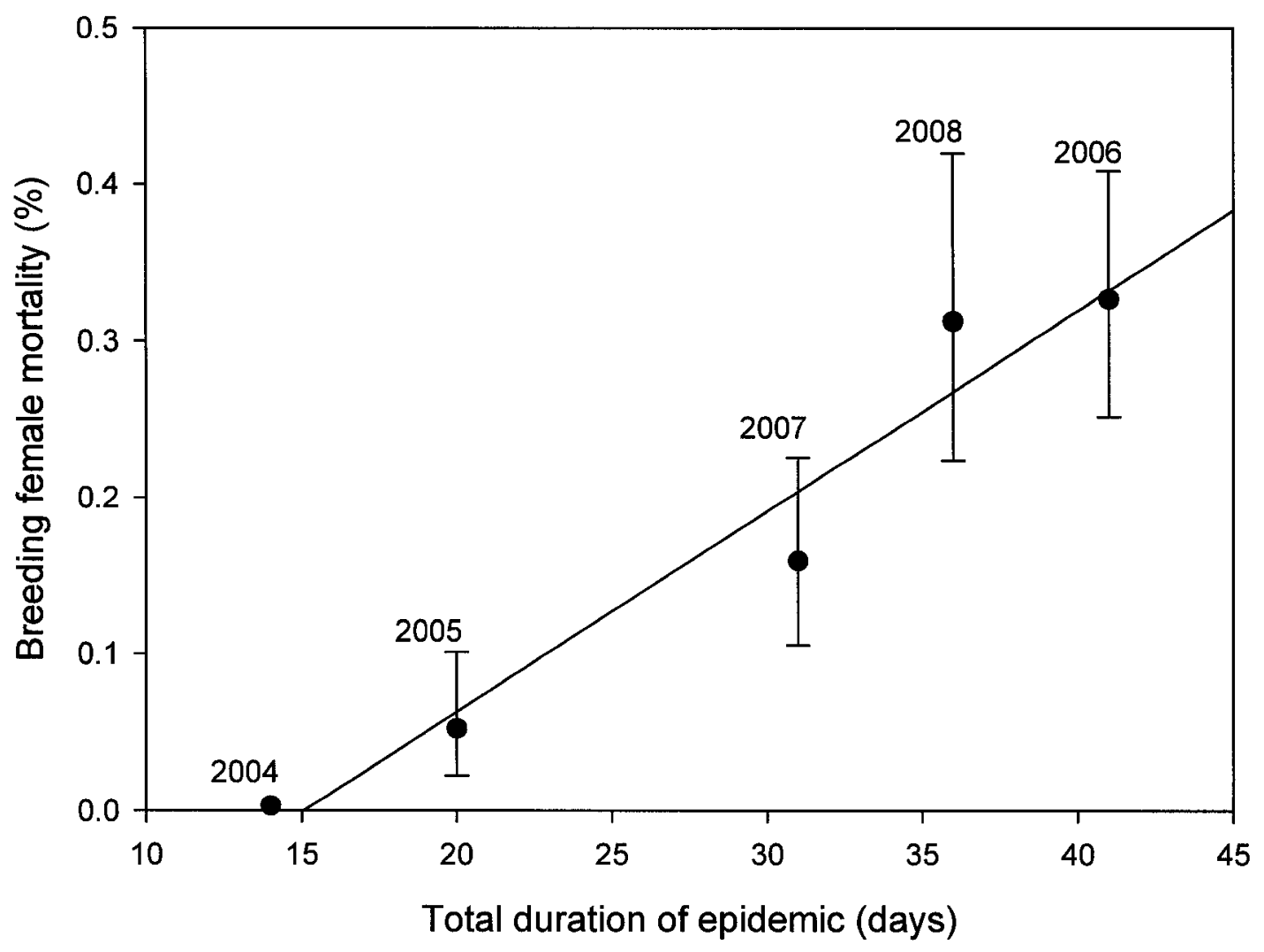

Figure 3. Annual percent mortality $( \pm 95 \%$ CI) among breeding female Common Eiders is shown in relation to the duration that nesting hens were present on the island in the presence of avian cholera induced mortalities. The duration of the epizootic is defined as the number of days elapsed between the first mortality detected on the island and the day on which the last nest fledged ducklings in the permanent nest monitoring plots. 


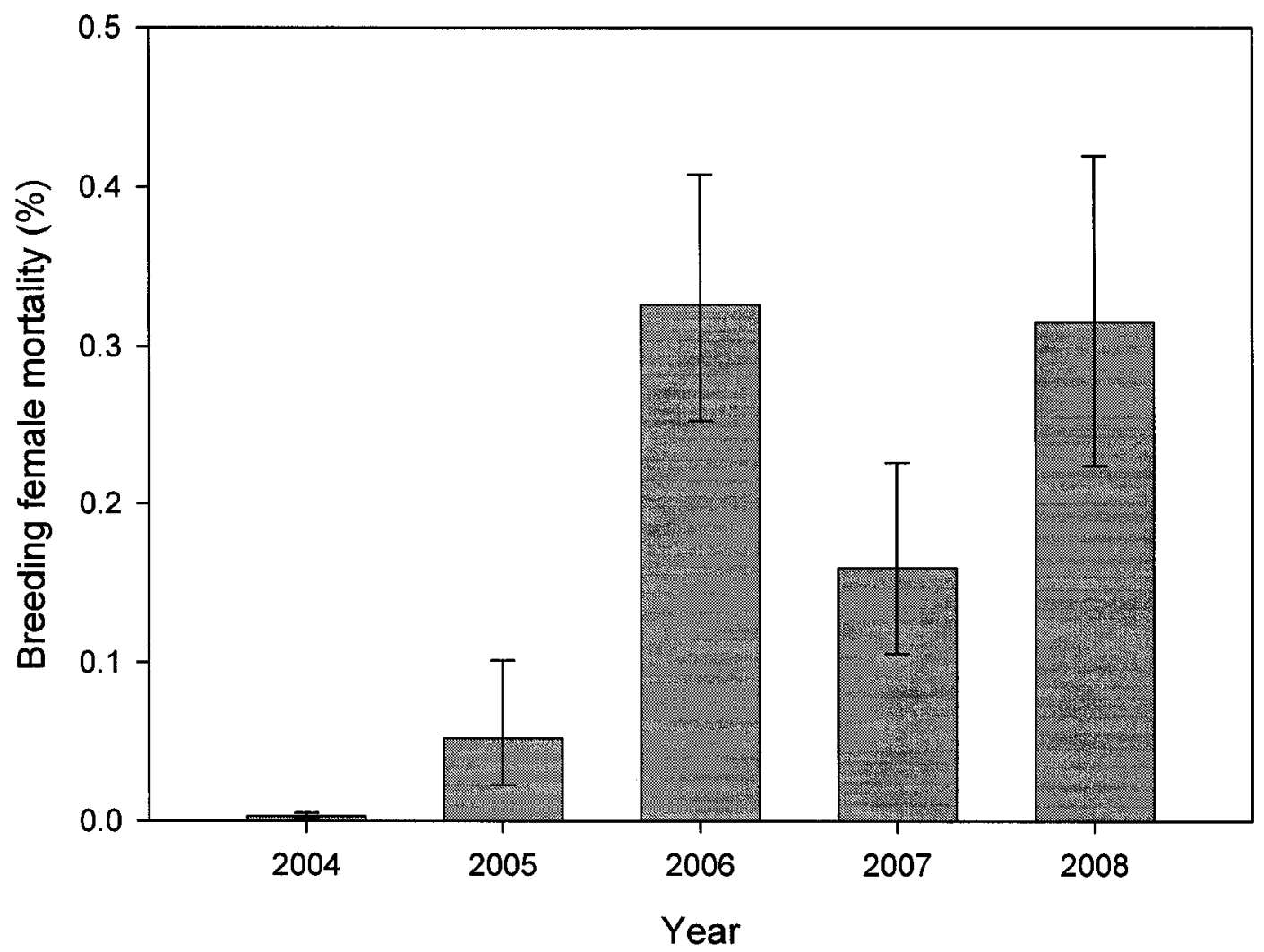

Figure 4. Percent mortality among breeding female Common Eiders between 2004 and 2008. Error bars represent $95 \%$ confidence intervals. 


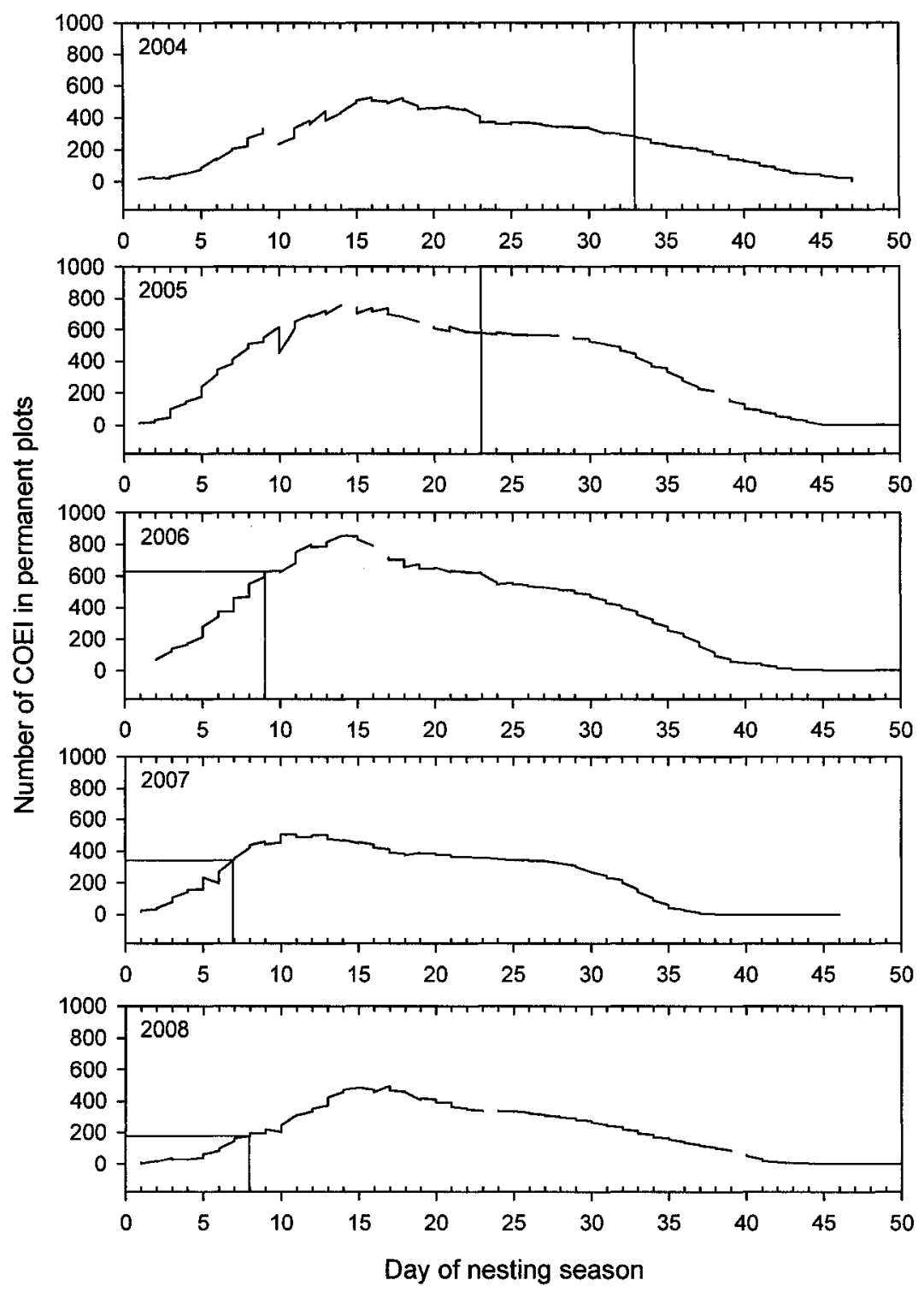

Figure 5. Number of Common Eider (nesting females and attending male) observed in five permanent nest monitoring plots ( $7.9 \%$ of nesting area of the island). Day of nesting season is the number of days since the first nest was detected in one of the permanent plots. Vertical lines represent the day the first avian cholera mortality was detected on the island. Between 2006 and 2008, the first avian cholera mortality was observed before the number of birds on the island peaked. The number of birds present in all permanent plots at the time of the first avian cholera mortality is emphasized by the horizontal lines intersecting the yaxis. 


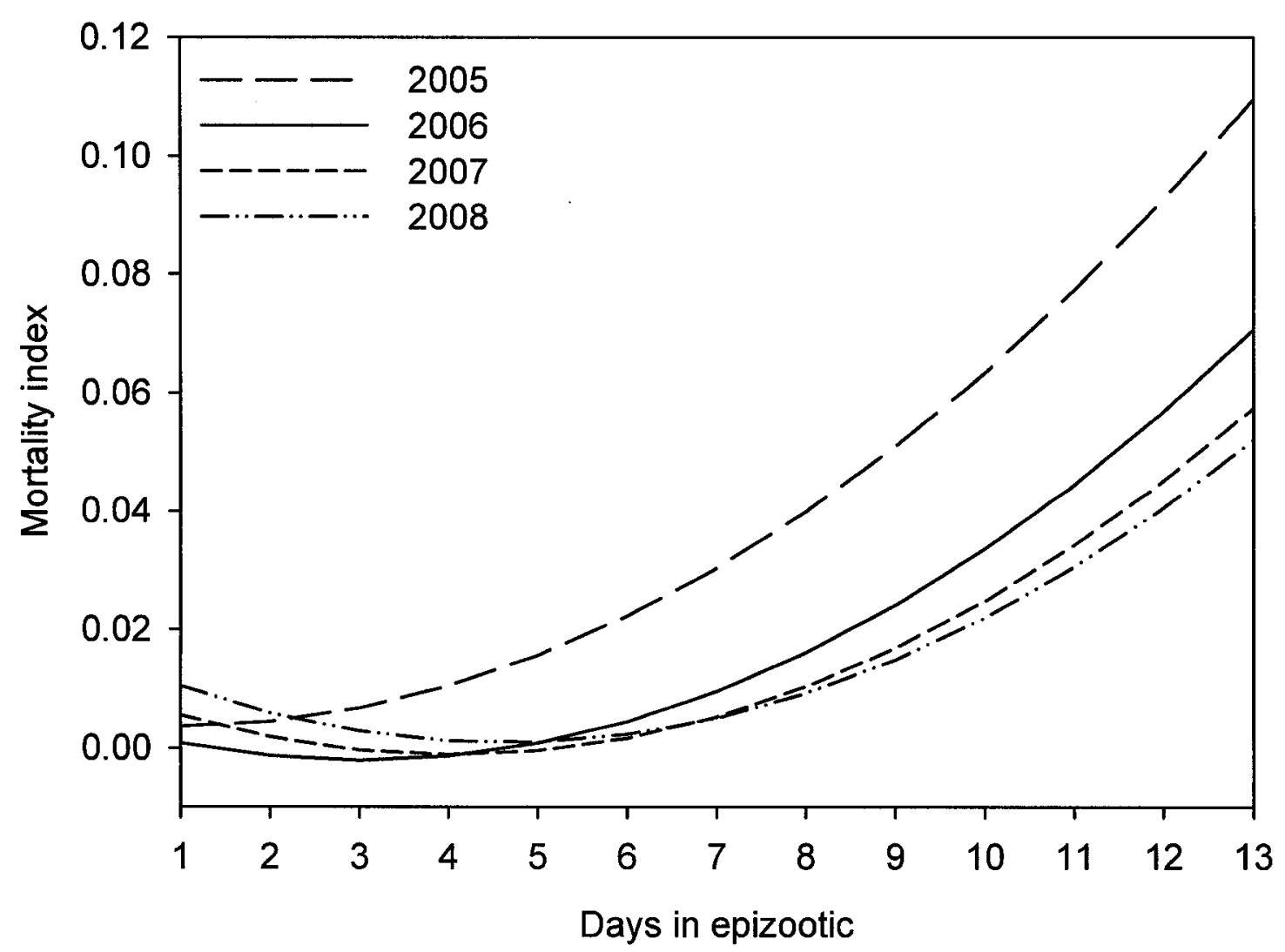

Figure 6. Rate of mortality during the first 13 days of the epizootics 2005 to 2008 as estimated by the quadratic model 'mortality index' = 'day of epiozootic' + 'day of epizootic ${ }^{2}$ + 'year' + 'year'*'day of epizootic' (GLM). Day 1 of the epizootic is the day on which the first mortality on the colony was recorded. Mortality index was calculated as 'no. of fresh carcasses / live birds in permanent plots'. 


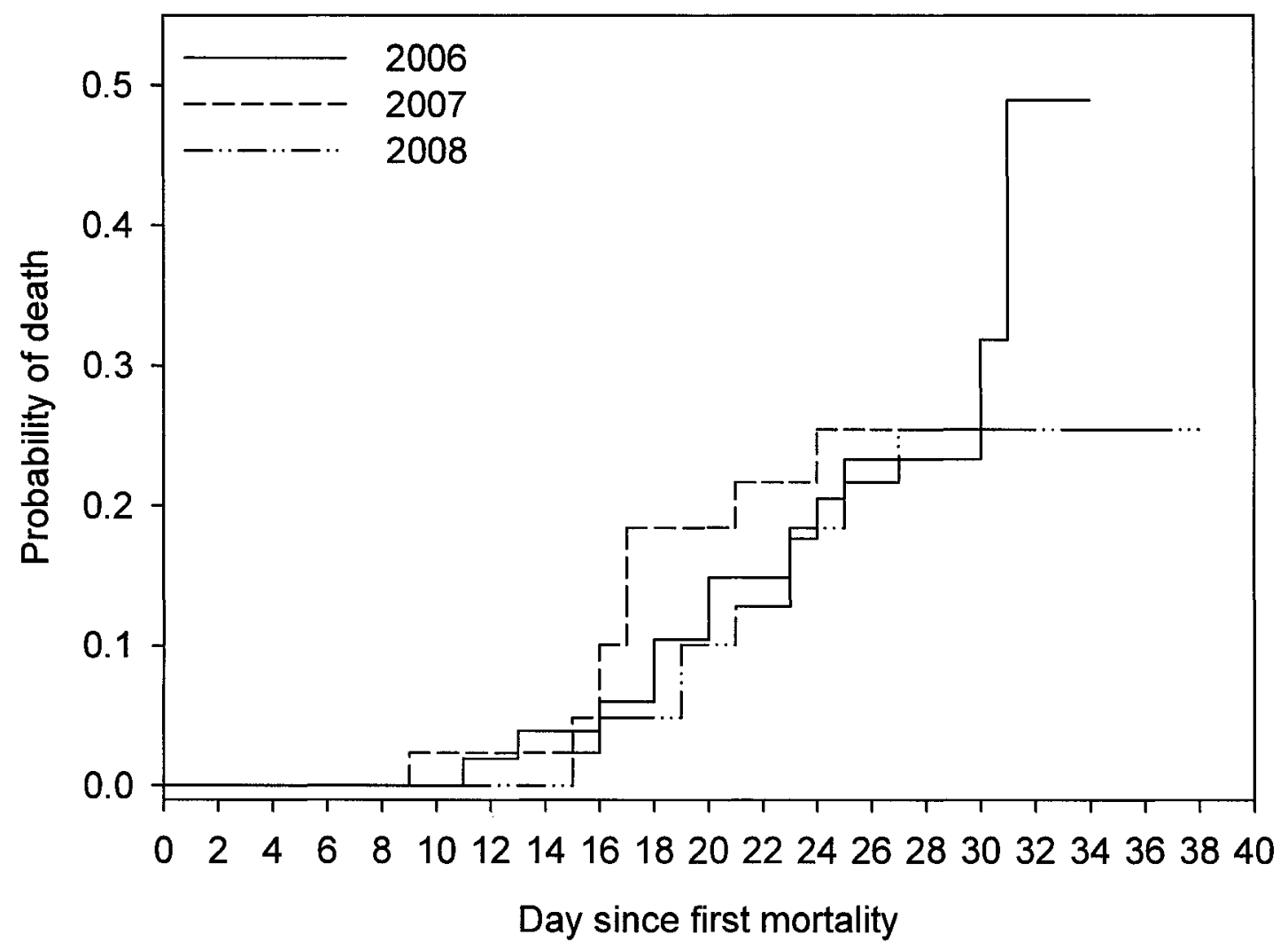

Figure 7. Probability of death (1-survival Kaplan-Meier survival function) increased in all years (2006 to 2008) with the number of days since the first mortality was observed on the island. 


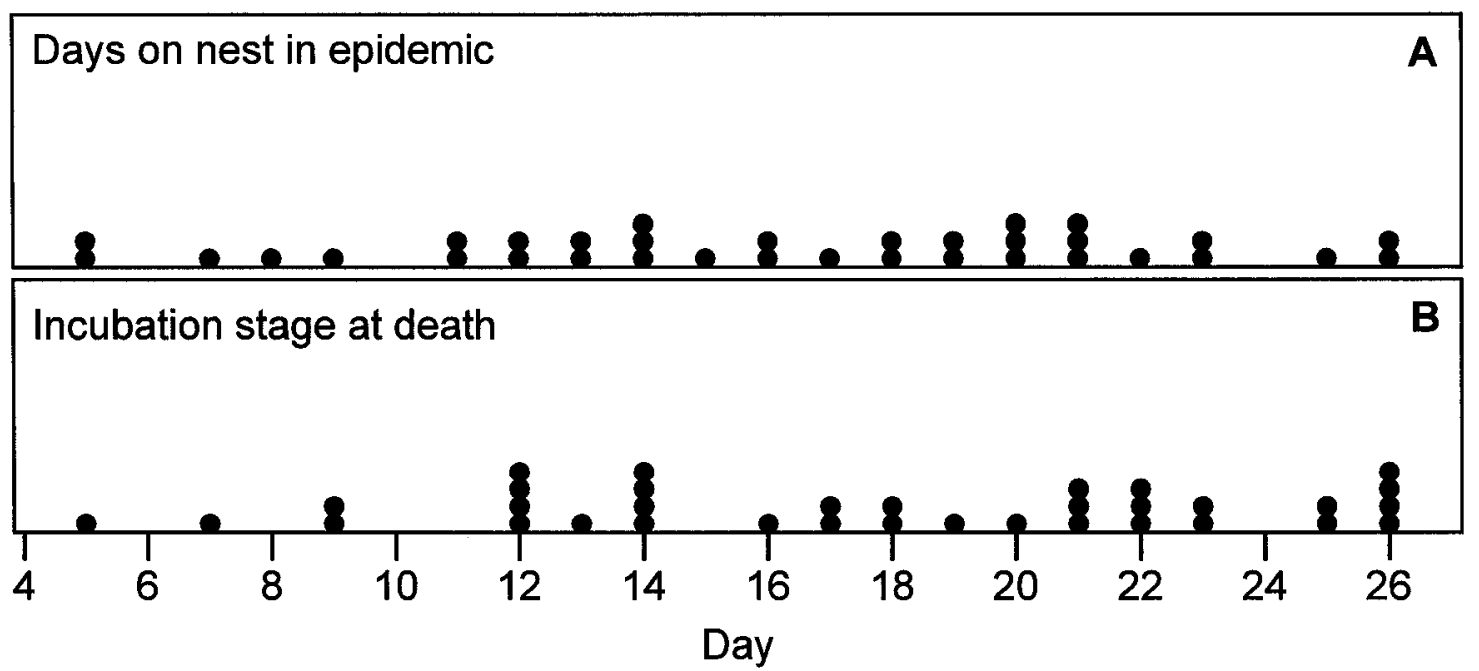

Figure 8. Frequency distribution of the number of days that hens that died had spent on their nests during the epizootic (A) and the frequency distribution of the incubation stage at death (B) pooled for the years 2006 to 2008. Each black dot represents the death of one hen. 


\section{CHAPTER 3}

\section{HANDLING STRESS LOWERS SURVIVAL AND DELAYS REPRODUCTION OF BREEDING FEMALE COMMON EIDERS SOMATERIA MOLLISSIMA DURING AN AVIAN CHOLERA OUTBREAK}

- based on a manuscript of the same title submitted to the Journal of Applied Ecology.

\section{INTRODUCTION}

Mounting a stress response is often detrimental to immune function (Dhabhar and McEwen et al. 1997, Wingfield et al. 1998, Nelson et al. 2002) and it has been proposed that this stress induced reduction of immune function may result from a reallocation of resources towards a higher metabolic rate and/or towards subsequent reestablishment of homeostasis (Nelson et al. 2002, Sheldon and Verhulst 1996, for alternative hypotheses see Svensson et al. 1998, Råberg et al. 1998, Sapolsky et al. 2000). The magnitude of the stress response increases with the severity of the stressor (Silverin 1998, Wingfield and Farner 1993) but it is thought that the physiological changes induced by stress disappear after removal and/or evasion of the stressor (Wingfield et al. 1998, Silverin 1998), a process that may last for weeks (Sapolsky et al. 2000). For example, great tits Parus major handled repeatedly exhibit elevated breathing rates, indicative of physiological stress, 30 days after handling experiments (van Oers and Carere 2007). Additionally, animals often increase foraging and/or suspend or forego energetically costly breeding behaviours following stress exposure to promote survival (e.g. Wingfield et al. 1998) suggesting that temporary stress can affect individuals over long time periods and may 
lead to a reduction in reproductive fitness. Researchers studying animals often impose handling stress and the effects of this stress is often considered, but not evaluated directly. Therefore, the long-term consequences of stress on the fitness of individuals in the wild are understudied but might manifest in at least two ways: a stressed animal might delay or abandon its breeding efforts and/or might not be able to respond adequately to natural pathogens because of compromised immunity.

Stress-induced immunosuppression is thought to play an important role in disease processes in the wild (McEwen et al. 1997, see also Botzler 1991). One of the most important diseases occurring among North American waterfowl is avian cholera, which is highly contagious and caused by the bacterium Pasteurella multocida (Friend 1999, review in Samuel et al. 2007). Even though P. multocida is highly virulent, some birds successfully fight infection (Reed and Cousineau 1967) by activating the humoral immune response (Harper et al. 2006). Stress, however, can depress humoral immune function (McEwen et al. 1997, Bourgeon et al. 2006a, Svensson et al. 1998) and immune function is suppressed following experimental exposure to the stress hormone corticosterone (Bourgeon and Raclot 2006). Therefore, stress might increase an individual's susceptibility to an avian cholera infection and mortality (see also Descamps et al. 2009). However, the effects of stress (or quantifiable surrogates) on the survival and fitness of birds in the presence of a disease have, to my knowledge, not been examined in the wild.

Common Eiders Somateria mollissima nesting colonially on East Bay Island have experienced confirmed annual avian cholera epizootics since 2005. Incubating female Common Eiders rely solely on endogenous reserves accumulated in part near the colony 
(Edith Sénéchal, Joël Bêty, and Grant Gilchrist, unpublished data) prior to the 23 to 30 day incubation period. During incubation, fasting hens are resource limited and experience declines in humoral immune function (Hanssen et al. 2004, Bourgeon et al. 2006a, 2006b). Due to its immunosuppressive effect, stress may augment disease susceptibility in eiders which opt to breed. The East Bay colony, therefore, constitutes an ideal system to address the question of whether acute stress experienced prior to nest initiation increases the probability of mortality from avian cholera. To promote survival, however, hens may choose to skip costly breeding (Wingfield et al. 1998, see also Lancaster et al. 2008). Alternatively, hens may choose to breed but delay egg-laying following a stress episode (Wingfield et al. 1998, Salvante and Williams 2003). This behavioural response to stress may allow hens to recover from the stress episode and thus increase their survival probability in the ensuing avian cholera epizootic.

Here, I examined the impact of handling stress on breeding propensity, nest initiation, and the ability of an individual hen to survive disease exposure over time, using restraint duration as a proxy for the stress level experienced by female Common Eiders (Wingfield et al. 1995, Wilson and Gaston 2001). Following their release, the breeding status (i.e. breeder or non-breeder) and time of nest initiation of handled hens was determined and their ability to resist and/or fight infection was assessed by monitoring their fate (i.e. death or survival). I subsequently examined whether stress induced behavioural changes enhanced a breeding hen's survival. Thus, I experimentally tested the following predictions: 1) longer restraint duration prior to nesting should increase the probability of death among female Common Eiders during the avian cholera epizootic, 2) female eiders should skip breeding or delay nest-initiation in response to 
longer restraint duration, and 3) for a given restraint duration, stress induced delay in incubation should enhance female survival.

\section{METHODS}

\section{Capture and processing of eider ducks}

Common Eiders were captured during pre-laying and early laying between June 18 to July 5 (2007) and June 13 to June 16 (2008). Once caught, eiders were immediately extracted for processing. Females were nasal-tagged and all birds were banded and morphometric measurements (length of tarsometatarsal bone, flattened wing chord, length from the occipital ridge to the tip of the bill, and lengths of bill, culmen and nostril) were taken. Blood samples and cloacal and choanal swabs were obtained for other studies. Hens waiting to be processed were held individually in the dark within plywood boxes $(45 \mathrm{~cm} \times 45 \mathrm{~cm} \times 60 \mathrm{~cm})$ lined with snow to reduce heat stress. Restraint duration was recorded as the time elapsed from initial capture at the net until final release. In 2007 , restraint duration ranged from $30 \mathrm{~min}$ to $158 \mathrm{~min}$. In 2008 , restraint duration was reduced to less that $87 \mathrm{~min}$ to minimize any negative effects of handling.

\section{Monitoring mortality}

To identify breeding nasal-tagged hens and to monitor their fate, the island was scanned twice daily with spotting scopes from observation blinds. Any hen not recovered dead during the nesting season was considered to have survived the epizootic. Indeed, offisland mortality is likely to be low: survival analysis from this study site showed that survival probability of nasal-tagged breeders that were not found dead on the island 
during the avian cholera years 2006 and 2007 did not differ from the survival probability of nasal-tagged hens breeding in years without avian cholera 2002-2004 (unpublished data).

Mortality observed among nasal-tagged breeding hens differed between the years with $16 \%$ succumbing to the disease in 2007 compared to $32 \%$ in 2008 . The levels of mortality observed among the handled birds was representative of the mortality recorded among the entire nesting population. Despite similar estimated colony size (2007: 6200 pairs; 2008: 5800 pairs) half as many carcasses were recovered in 2007 than in 2008 during a post-breeding survey of the entire island (2007: 781; 2008: 1454; see Chapter 2).

\section{Statistical methods}

To determine whether longer restraint duration affected survival and/or reproduction of female eider ducks, I performed logistic regressions (with survival and breeding probabilities as dependent variables, $\mathrm{n}=229$ and 518 respectively) and a general linear model (GLM, with laying date as dependent variable, $\mathrm{n}=110)$ with 'restraint duration' (min), 'capture date' (ordinal day where January $1=1$ ), 'year' (coded as binary dummy variable), and the first-order interaction, 'restraint duration $\times$ year', as independent variables. 'Capture date' was included because restraint duration decreased with capture date in 2007 (Spearman's rank correlation coefficient $=-0.174, \mathrm{P}=0.042, \mathrm{n}=137$ ), so that capture date could confound my results. Overall percent mortality and restraint duration differed significantly between years ( $\%$ mortality: Log-likelihood ratio $=12.391$, d.f. $=1, P<0.001, n=137$; restraint duration, square-root transformed: $t$-test with unequal variances: $\left.t_{225.561}=12.892, \mathrm{P}<0.001\right)$. Therefore, the variable 'year' and the first 
order interaction between 'year' and 'restraint duration' were included to test whether the effect of restraint duration varied between years.

Finally, I investigated whether a stress induced delay to egg-laying can enhance survival by using a logistic regression with the 'time from capture to egg-laying' (in days), 'restraint duration', and 'year' as independent variables $(\mathrm{n}=110)$. I also included the first order interaction 'year $\times$ time from capture to egg-laying' to investigate whether time from capture to egg-laying affected an individual's probability of death (for a given laying date and restrain duration) differently between years.

Infection at the banding station likely did not occur as mortality among eiders that were not captured was comparable to the mortality of restrained hens (see Monitoring mortality, p.44) and there was no mortality within 2 days after handling, the time window within which avian cholera mortality usually ensues (Samuel et al. 2007). Nesting nasaltagged hens that were subsequently recovered dead, were last seen on their nests 13 to 41 days after release in 2007 (mean: $27.72 \pm 1.621, \mathrm{n}=18$ ) and 5 to 33 days after release in 2008 (mean: $21.53 \pm 1.292, \mathrm{n}=30$ ). Nasal-tagged hens whose exact death dates are known died within the same time window (2007: $13-41$ days, $\mathrm{n}=9 ; 2008: 7-32$ days, $\mathrm{n}=13$ ). Overall, of all monitored nasal-tagged breeders for which holding times were available in $2007(\mathrm{n}=137), 18$ hens died. In 2008, all measurements were available for 93 hens, 30 of which died.

All analyses were performed using SPSS 15.0 (SPSS Inc., Chicago, IL). Logistic regressions were performed using the generalized linear model procedure; coefficients of dispersion ( $\hat{C}$ ) were close to 1 (range: $0.9-1.3$ ) which indicates that my results did not suffer from over- or under-dispersion. For GLM, homogeneity of variances was assessed 
with the Levene's test $\left(F_{1,108}=2.209, P=0.140\right)$ and normality of residuals was evaluated using the Shapiro-Wilk test $\left(\mathrm{W}_{108}=0.986, \mathrm{P}=0.304\right)$. Mean values are given as means \pm standard errors (SE). Results were considered significant at $\mathrm{P}<0.05$ and all tests were two-tailed.

\section{RESULTS}

\section{Restraint duration and mortality}

The effect of restraint duration on the probability of death was significantly different between years (effect of the interaction year $\times$ restraint duration: Wald $\chi^{2}{ }_{1}=5.698, \mathrm{P}=$ 0.017). In 2007 , longer restraint duration significantly increased the likelihood of death (Wald $\chi_{1}^{2}=4.425, P=0.035$, slope: $0.018 \pm 0.0085$, Figure 9) and an increase in restraint duration by 10 minutes increased the probability of mortality by an estimated $1 \%$ to $4 \%$ (Figure 9). In 2008, restraint duration did not affect the probability of death (Wald $\chi_{1}^{2}=$ $2.472, \mathrm{P}=0.116)$. The probability of death was not affected by capture date (Wald $\chi_{1}^{2}=$ $0.097, P=0.755)$ but year significantly affected the probability of death (Wald $\chi_{1}^{2}=$ 12.211, $\mathrm{P}<0.001)$

\section{Restraint duration and breeding probability}

Neither restraint duration nor year significantly affected the probability to breed (restraint duration: Wald $\chi_{1}^{2}=2.140, \mathrm{P}=0.144$; year: Wald $\left.\chi_{1}^{2}=0.196, \mathrm{P}=0.658\right)$ and the effect of restraint duration on breeding probability did not differ between years (effect of the interaction year $\times$ holding time: Wald $\chi_{1}^{2}=2.70, \mathrm{P}=0.603$ ). However, hens captured late 
in the season were less likely to breed than hens captured earlier (Wald $\chi_{1}^{2}=9.829, \mathrm{P}=$ 0.002$, slope $=-0.065 \pm 0.0208)$.

\section{Restraint duration and egg-laying onset}

Restraint duration did significantly increase the time lag between capture and egg-laying $\left(\mathrm{F}_{1,105}=6.207, \mathrm{P}=0.014\right.$; Figure 10$)$ and this effect of restraint duration on the timing of egg-laying did not differ between years $\left(F_{1,105}=2.180, P=0.143\right)$. An increase of 10 minutes led to an estimated delay of 0.5 days (see Figure 10). Hens captured late in the season started egg-laying significantly sooner after capture than hens captured early in the season $\left(F_{1,105}=42.057, P<0.001\right)$ and hens captured in 2007 delayed $5.8 \pm 2.660$ days more than hens captured in $2008(\mathrm{t}=2.179, \mathrm{P}=0.032)$.

\section{Time delay between capture and egg-laying and death probability}

Time delay between capture and egg-laying did not affect an individual's probability of death (Wald $\chi_{1}^{2}=0.791, \mathrm{P}=0.374 ; 2007:$ Wald $\chi_{1}^{2}=0.248, \mathrm{P}=0.618 ; 2008:$ Wald $\chi_{1}^{2}=$ 2.598, $\mathrm{P}=0.107$ ) whichever year is considered (interaction year $\times$ holding time: Wald $\chi_{1}^{2}$ $=2.434, \mathrm{P}=0.119)$. The effect of restraint duration was not significant (Wald $\chi_{1}^{2}=$ $2.262, \mathrm{P}=0.133$ ) and an individual's probability of death (for a given restraint duration and time delay between capture and egg-laying) varied between years (Wald $\chi^{2}{ }_{1}=6.172$, $P=0.013)$ 


\section{DISCUSSION}

\section{Effect on survival}

Handling stress increased the likelihood that eiders, subsequently exposed to avian cholera, succumbed to the disease (Figure 9). These findings are consistent with predictions that an acute stressor, such as handling and restraint, can have long term negative effects on animals (van Oers and Carere 2007) and suggest that fitness costs incurred by eiders in response to stress include a reduction of immune function, in particular possibly of humoral immunity important in resisting avian cholera (Harper et al. 2006). An immunosuppressive effect of stress has long been recognized (McEwen et al. 1997, Wingfield et al. 1998, Silverin 1998, Sapolsky et al. 2000); however, to my knowledge, the detrimental effect of such a stress response on the fitness of animals has not been previously demonstrated in the wild.

It has been proposed that a stress induced reduction in immune function is mediated by a reallocation of resources from immunity to the stress response and the reestablishment of homeostasis (Nelson et al. 2002, Sheldon and Verhulst 1996). In my study, birds were captured and restrained immediately prior to nesting. Common Eiders are capital nesters relying entirely on their endogenous resources accumulated prior to nesting (Edith Sénéchal, Joël Bêty, and Grant Gilchrist, unpublished data), thus often loosing up to $45 \%$ of their initial body mass at this site during the 23 to 30 day incubation period (Bottitta et al. 2003). It has been shown that an immune challenge can indeed be costly, leading to increased metabolic rate (House Sparrows, Passer domesticus: Martin II et al. 2003), higher rates of mass loss (Common Eiders: Hanssen 2006) and decreased 
rates of return the following year (Common Eiders: Hanssen et al. 2004). Fever is also known to be an energetically costly condition (Owen-Ashley and Wingfield 2007) and constitutes one of the first line defenses in response to an infection with $P$. multocida, in particular (Samuel et al. 2007). The resources needed to mount an effective immune response might well be lacking in a fasting eider hen that has undergone an energetically costly, immunosuppressive stress event and later becomes exposed to disease. Therefore, the long-term detrimental impact of acute stress on survival, as has been observed in my study in 2007 , may be due to stress-induced depletion of limited resources prior to nesting.

In order to prevent a negative impact of handling stress on eider hens in 2008 , restraint duration was nearly halved when compared to 2007. As expected, restraint duration did not affect subsequent survival of incubating eider hens in 2008. However, mortality among breeding hens was twice as high in $2008(32 \%)$ than in $2007(16 \%$;

Chapter 2) suggesting that the risk of infection was heightened for all hens in 2008 when compared to 2007, irrespective of the stress level experienced prior to the nesting season. Due to the confounding effect of disease severity, I am unable to determine whether the lack of a positive relationship between restraint duration and mortality in 2008 was determined by the shortening of the restraint duration or by the greater severity of the ensuing avian cholera epizootic. It is possible, that in a year of moderate mortality an effect of handling stress on survival may have been detectable. 


\section{Effect on reproductive behaviour}

Female Common Eiders did not forgo breeding in response to the stress experienced prior to breeding during capture and handling but delayed egg-laying (Figure 10). A similar behavioural modification was observed among female and male Thick-billed Murres Uria lomvia, which increased the time they remained absent from their nesting site in response to handling stress (Wilson and Gaston 2001). Elevated stress hormones can suppress breeding activity and may promote gonadal regression (Wingfield and Farner 1993). Therefore, stress hormones may need to return to base levels before individuals can resume breeding leading to the observed delay in egg-laying. Alternatively, elevated stress hormone levels can increase feeding rates (Wingfield et al. 1998, Sapolsky et al. 2000) and increased food intake can ameliorate the stress response (Romero and Romero 2002). At East Bay, female Common Eiders feed near the breeding colony just prior to egg-laying (Edith Sénéchal, Joël Bêty, and Grant Gilchrist, unpublished data). It is possible that hens, by delaying egg-laying, increased their food intake following the stress event. However, in my study, I could not ascertain that a delay in egg-laying ameliorates the negative effects of handling stress as I did not detect a significant negative relationship between the lag time between capture and egg-laying and a hen's subsequent probability of death. Yet, even though insignificant, my results suggest that the overall probability of mortality decreased in 2008 with delay to egg-laying. If such a relationship exists, it is likely to be limited and the doubled risk of mortality in 2008 when compared to 2007 may have negated any beneficial effects of delayed egg-laying on survival in 2008. I observed no apparent effect of egg-laying delay on female survival in 2007 when restraint duration was twice as long as in 2008. As the stress response 
increases with the severity of the stressor (Silverin 1998) and a delay in egg-laying can result in decreased survival of the young (e.g. Lepage et al. 2000), the duration hens were able to delay without trading-off juvenile survival may not have been sufficient to affect survival during the ensuing avian cholera epizootic in 2007 even though hens in this year delayed egg-laying longer than hens in 2008. The proximate mechanisms involved in causing a delay in egg-laying and a possible relationship between stress intensity, stressinduced behaviour modification, and subsequent measures of fitness warrants further investigation.

\section{Conclusion}

My results indicate that stress can have a long-term negative impact on an animal's susceptibility to disease and its ultimate survival, thus emphasizing the importance of minimizing handling times and of including control treatments in experimental studies involving prolonged or repeated handling of study animals to avoid attributing fitness costs incurred by stress experienced during the handling procedure to treatment effects. The ultimate costs of being restrained, however, might be a function of the environmental conditions. Restraint durations of several hours are not uncommon during waterfowl research (e.g. Sedinger et al. 1997), but they may not lead to decreased fitness/survival of adults under benign conditions (e.g. Brant goose Branta bernicla nigricans: Sedinger et al. 1997). Among Common Eiders at East Bay, for example, no decline in survival was observed among blood sampled females that were subsequently experimentally restrained for 24 hours immediately prior to breeding (Joël Bêty, Grant Gilchrist, and Sébastien Descamps, unpublished data) suggesting that in the absence of disease, survival costs of 
handling are low. In the presence of a contagious disease, however, costs of handling may be high and behavioural coping mechanisms may not suffice to ensure survival.

Even in the absence of disease, a stress-induced delay in egg-laying, as has been observed in my study, can result in reduced fitness of the affected individual. For example, even small delays in lay-date led to a steep decline in reproductive success (the number of young surviving to the first winter) among Snow Geese Anser caerulescens atlanticus (Lepage et al. 2000). Thus, even disease-free populations are likely to experience reduced individual fitness in response to stress mediated by a delay in egglaying. This emphasizes the importance of considering the effect of restraint and handling on individual fitness in animal studies. 
FIGURES

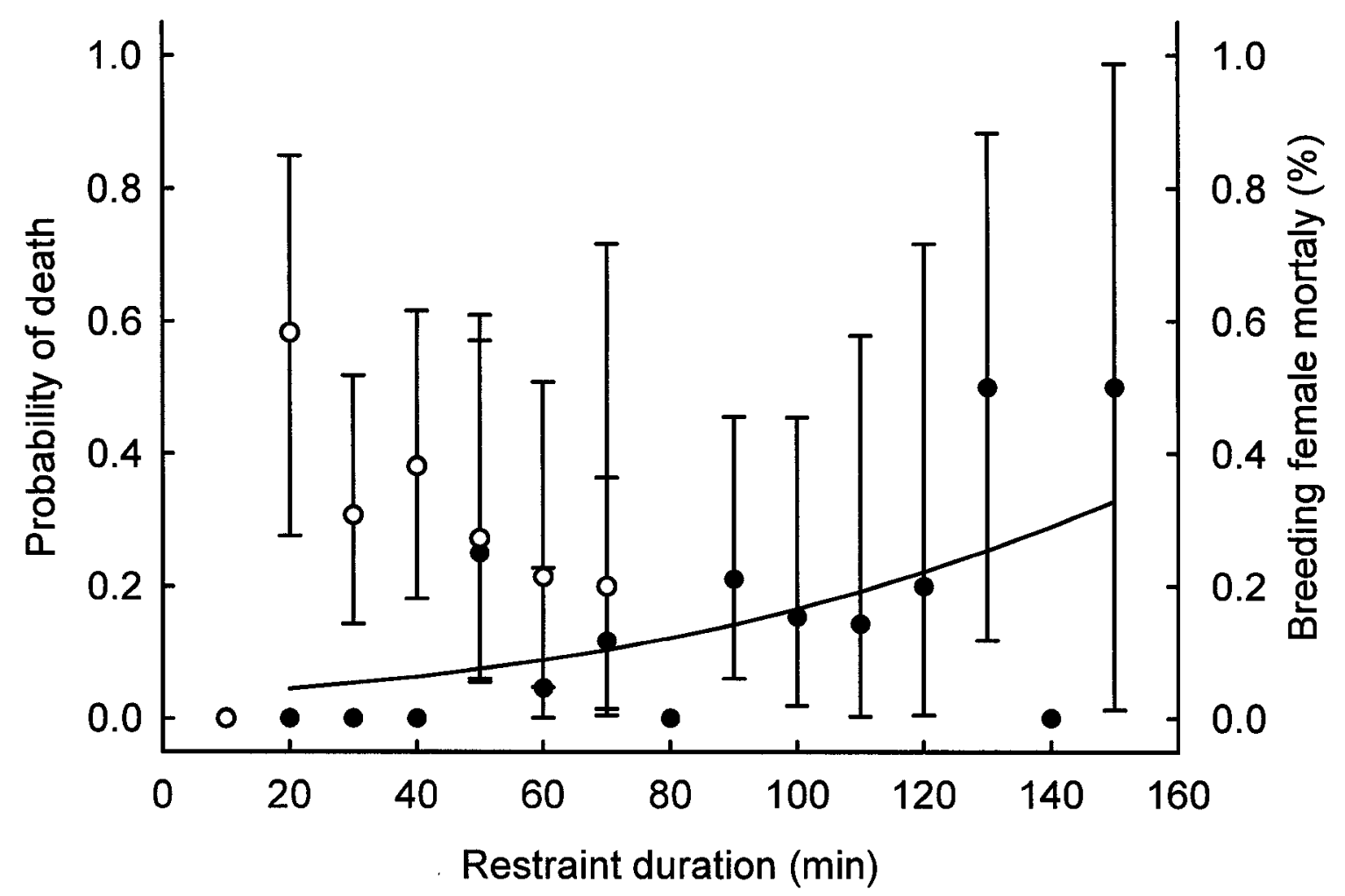

Figure 9. Percent mortality among breeding hens for each $10 \mathrm{~min}$ restraint duration interval in the years 2007 (black circles) and 2008 (white circles) and the 2007 probability of death (solid line) obtained from the model: logit (probability of death) $=-3.415+0.018 *$ restraint duration $+3.639 *$ year $-0.042 *$ restraint duration $\times$ year. Error bars represent the $95 \%$ confidence intervals. 


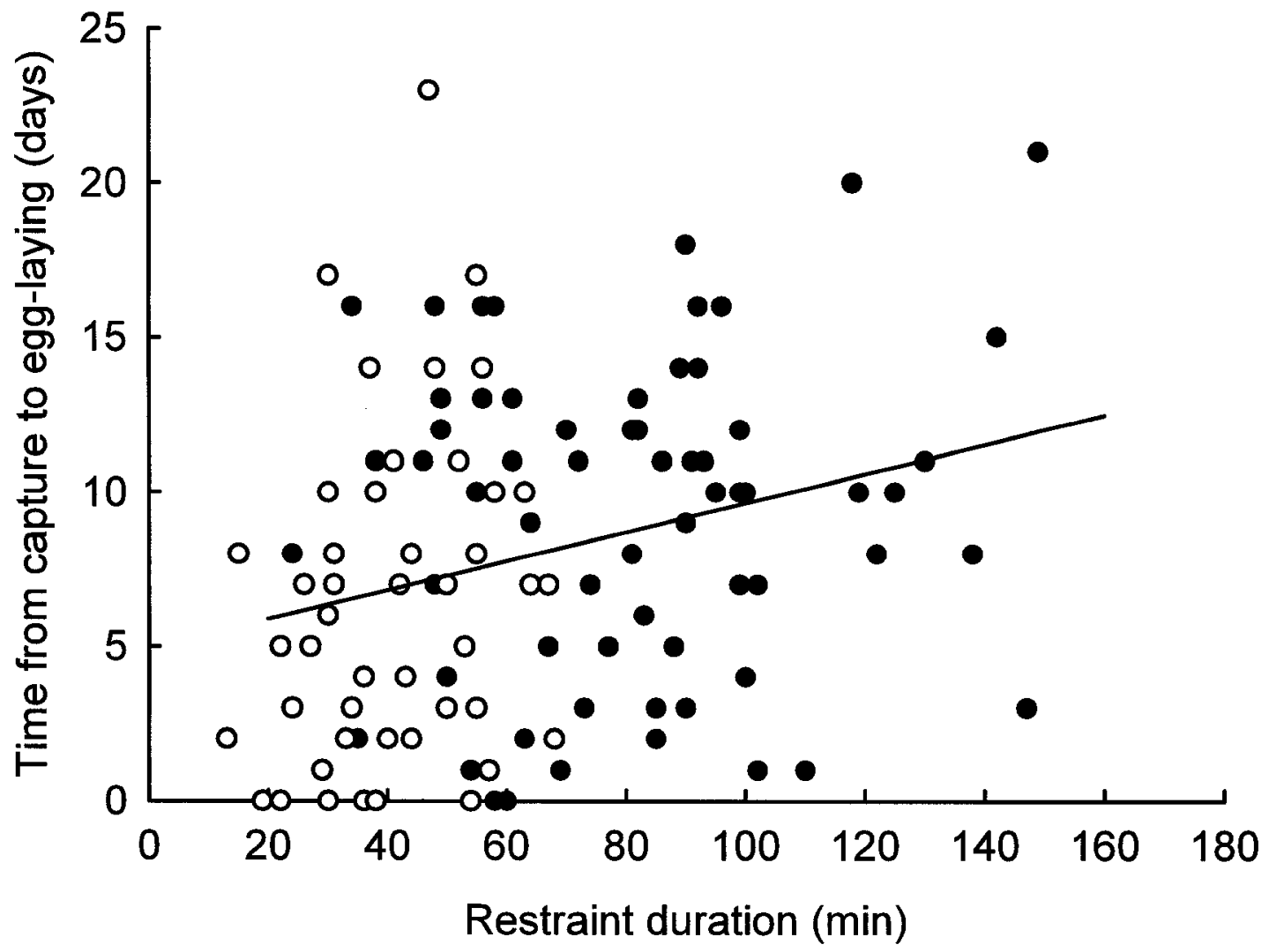

Figure 10. Time elapsed between capture and egg-laying in the years 2007 (black circles) and 2008 (white circles as it relates to restraint duration. Regression line (2007 and 2008, solid line) was obtained from the GLM model: time from capture to egg-laying' $=4.250+0.047^{*}$ restraint duration. 


\section{CHAPTER 4}

\section{General Discussion}

In recent years, wildlife diseases are emerging in new geographical regions and are occurring at unprecedented frequency in new populations (Friend et al. 2001). Since it was first detected among wild waterfowl in Texas in 1944 (Gordus 1993), avian cholera has continuously spread northward and eastward across North America (Friend 1999). Even though avian cholera has been reported in arctic nesting Snow Geese (Samuel et al. 1999), mass mortalities among arctic nesting Common Eiders have been rare prior to 2004 (Goudie et al. 2000, Henri 2007). In 2004, avian cholera emerged among arctic nesting Common Eiders and has since occurred annually at the East Bay Island breeding colony located in northern Hudson Bay.

Avian outbreaks have primarily been observed on the wintering and staging grounds of waterfowl where many different species and subpopulations aggregate and the movement of birds among wetlands is great (e.g. Blanchong et al. 2006a). Therefore, it has been difficult to understand factors contributing to the occurrence of epizootics, to examine the dynamics of disease outbreaks and to assess the impact of the disease on bird populations (Samuel et al. 2007). Where the disease has occurred among breeding populations, only mortality could be assessed (e.g. Gershman et al. 1964, Reed and Cousineau 1967, Pedersen et al. 2003), and carcasses were sometimes burned throughout ongoing epizootics to control mortality (Waller and Underhill 2007). This thesis provides the first attempt to describe the annual and inter-annual dynamics of the disease within the distinct breeding population of Common Eiders nesting at East Bay Island and is the 
first to experimentally examine the role of stress in contributing to avian cholera mortality.

In summary, first mortalities at the site were observed in 2004 after the East Bay Island population had experienced an annual increase of $16.9 \%$ since 2000 , growing from an estimated 3323 to 5856 pairs. First mortalities during the annual epizootics occurred progressively earlier in relation to the breeding phenology of the eiders between the years 2004 and 2006. Between 2006 and 2008, the onset dates of the epizootics varied little relative to the eiders' breeding cycle. The initial rate of mortality during the first 13 days of the epizootics increased non-linearly, and this increase was steeper in 2005 than in any subsequent year. Between 2005 and 2007, the serotype of the bacteria causing mortality shifted from serotype 1 in 2005 to serotype $3 \times 4$ in 2007 with both serotypes being present in 2006. Population density did not affect the onset dates of the epizootics over the years nor did population size affect total annual mortality. Instead, total annual mortality was linearly related to the duration of the epizootics within years. Mortality among breeding females increased from less than $0.5 \%$ in 2004 to $32.7 \%$ in 2006 . Mortality abated somewhat in 2007 with $16.5 \%$ of all breeding females succumbing to the disease, but mortality was high again in 2008 when $31.6 \%$ of all breeding females died. Overall, repeated avian cholera mortality has reduced the East Bay Island Common Eider breeding population by $32.2 \%$ since 2006 (Chapter 2). Handling did not affect variability in avian cholera mortality; however, prolonging restraint duration increased the probability of individuals succumbing to the disease, suggesting that external stressors could contribute to the occurrence of avian cholera epizootics (Chapter 3). 


\section{EXPOSURE DURATION}

My findings highlight the importance of exposure duration in determining total mortality among affected wildlife populations once the disease has been established. The effect of exposure duration on avian cholera mortality may have been exaggerated by an increased risk of mortality with the progression of the disease (Chapter 2). Factors that might contribute to an increasing risk of mortality may include decreasing immune function, potentially increasing encounter rate, and changes in bacterial virulence and/or density with the advancement of the breeding season and disease duration. As the epizootic and the breeding season progress, bacterial virulence may increase (Matsumoto and Strain 1993) and bacteria may accumulate in the environment (e.g. Price and Brand 1984). At the same time, incubating Common Eiders may experience a decline in immune function (Hanssen et al. 2004, Bourgeon et al. 2006a, 2006b, Bourgeon and Raclot 2006) and increase the frequency of drink breaks (Bottitta 2001). Therefore, in addition to potentially encountering more virulent bacteria at higher density than at the start of the epizootic, hens late in incubation, exhibiting decreased resistance, would be more likely to encounter the pathogen.

At East Bay, I did not see any pattern in the number of days that hens had spent on their nest prior to death suggesting the lack of a relationship between the risk of mortality and behavioural and physiological changes throughout incubation (Chapter 2). However, individuals may vary in quality (Hanssen et al. 2003a, 2003b) and/or behaviour, masking a possible correlation. For example, hens with large clutches are more likely to succumb to the disease when mortality is severe, possibly due to the heightened cost associated with incubation (decreasing immune function), a greater likelihood of completing 
incubation (increasing exposure duration), or an increased need to take drinking breaks (increasing exposure frequency; Descamps et al.2009). The contribution of these factors to the increased risk of infection within a season will require further investigation.

\section{POPULATION DENSITY}

I have not found an effect of density on the annual mortality or the disease initiation dates at East Bay Island (Chapter 2), even though high density is thought to have been implicated in the precipitation of avian cholera epizootics elsewhere (e.g. Christensen et al. 1997, Blanchong et al. 2006a, Samuel et al. 2007). Diseases transmitted via densitydependent mechanisms may permit the persistence of their host population at reduced but viable numbers (e.g. Anderson and May 1978). By contrast, diseases that are transmitted independently of population density are predicted to severely reduce their host populations in numbers, possibly to the point of extirpation, particularly in the presence of infectious individuals, such as alternative host species and carrier birds, which maintain the disease within a population (McCallum et al. 2001, de Castro and Bolker 2005, Ryder et al. 2007). Avian cholera is thought to be responsible for severe population declines in yellow-nosed albatross Diomedea chlororhynchos (Weimerskirch 2004), to have contributed to population declines among European eiders $S$. m. mollissima (Desholm et al. 2002) and has caused a 32\% decline in population size at East Bay Island (Chapter 2). Overall, the long-term impact of avian cholera on arctic nesting eiders may depend on the presence of carrier birds and/or alternative hosts in the population and, more generally, on the ability of the pathogen to persist within the population. 


\section{BACTERIAL SEROTYPES}

Theoretical studies show that highly virulent pathogens may cease to persist in a population because hosts die quickly and, therefore, transmission to susceptible individuals is minimized (Ganusov and Antia 2003, Ryder et al. 2007). Pathogens of low virulence, on the contrary, often exhibit high prevalence, i.e. being carried by many surviving individuals, and are more likely to persist in their host population (Ryder et al. 2007). The replacement of $P$. multocida serotype 1 by $P$. multocida serotype $3 \times 4$ at East Bay (Chapter 2) may reflect differential bacterial virulence of the two serotypes. This suggests that the long-term impact of $P$. multocida on host abundance and persistence may differ by bacterial strain. Challenge trials conducted on Common Eiders using the different $P$. multocida strains isolated from the East Bay Island epizootics could shed light on the relative virulence of the different bacterial strains and on the birds' immune responses to such a challenge.

\section{IMMUNITY}

In addition to pathogen virulence, the development of protective immunity may regulate the course of a contagious disease within a population. In the presence of permanent protective immunity, it is predicted that epizootics may become cyclical as the number of available susceptible individuals is intermittently reduced (epidemic fade-out; LloydSmith et al. 2005). In this case, the level of mortality is being determined by the rate at which new susceptible individuals enter the population (Anderson and May 1979). In the presence of permanent immunity, total host mortality should decrease over time, a trend not yet seen in the East Bay Island population (Chapter 2). Also, in the presence of 
permanent immunity, mortality rate should differ by age as older birds are more likely to have encountered the pathogen than younger birds (Dobson and Hudson 1995).

It is unclear, whether permanent immunity to avian cholera can be acquired, but vaccines can provide temporary protection against infection (Samuel et al. 2007). The study of immunity to avian cholera is complicated by the fact that, even though antibodies can be detected in the blood, antibodies persist only for four weeks and current and past infections cannot be differentiated (Samuel et al. 2003a). In addition, it is difficult to determine the age of eiders (Goudie et al. 2000), knowledge of which would permit inferences to be made about the presence of permanent immunity in these birds. There is some evidence that in years of high avian cholera mortality, immature snow geese may be more likely to die than adults (McLandress 1983). At East Bay Island, avian cholera has been observed as the breeding population increased in size in response to harvest reductions in Greenland (Chapter 2; Flemming Merkel, personal communication). Prior to the shortening of the hunting season, juvenile eiders (1-year old) experienced prolonged hunting pressure when compared to adults, which migrated to their breeding grounds before the end and most intensive period of the hunting season (Merkel 2004b). Thus, if permanent immunity exists among older breeders, the population increase observed at East Bay may have constituted an influx of susceptible individuals. Survival analysis comparing apparent survival of hens nesting during and surviving an avian cholera epizootic to the survival of hens nesting prior to the avian cholera epizootic should provide some insight into whether permanent immunity might exist, whether harvest reductions in Greenland may have contributed to the recent avian 
cholera epizootics, and whether Common Eider populations can persist in the presence of avian cholera.

\section{STRESS AND DISEASE SUSCEPTIBILITY}

It is unclear what factors precipitated the recent avian cholera epizootics at East Bay Island. My findings show that restraint duration, which is known to induce a stress response (e.g. Wingfield et al. 1995), can decrease an individual's resistance to avian cholera and increase its probability of death in an ensuing avian cholera epizootic (Chapter 3). Changing environmental conditions, which are pronounced in the Arctic and North Atlantic due to climate change (reviewed in Barber et al. 2008, Greene et al. 2008), are often associated with the emergence of diseases (Friend et al. 2001); and both, pollutants (e.g. petrochemicals: Briggs et al. 1996, 1997) and stress induced by changing environments, can suppress immune function (e.g. McEwen et al. 1997, also see Smith et al. 2009). Interestingly, avian cholera and/or unusually high mortalities among nesting eiders have been reported concurrently in Digges Sound (avian cholera confirmed 2004: Gaston 2004), East Bay (avian cholera confirmed 2005: this study) and the northern Foxe Basin (Theo Ikummaq, personal communication, cause of death unidentified). I cannot exclude the possibility that the disease has been endemic, even though rare, within the arctic eider populations and that intermittent low rates of mortality have remained undetected and/or unreported. Mass mortalities attributed to lightening strikes are said to have occurred among Common Eiders around 1900 (Henri 2007) and substantial mortality of unknown cause has been witnessed on Common Eider colonies around Igloolik in the late 1950s (Rhoda Ungalak, personal communication). Therefore, carrier 
birds may have been present in the population and recent avian cholera epizootics may reflect changes in the susceptibility of Common Eiders to the disease rather than a new introduction of the disease into the arctic eider population. The examination of long-term environmental conditions, avian cholera mortality, and measures of stress may reveal possible correlations with the recent avian cholera outbreaks.

\section{ALTERNATIVE HOSTS AND CARRIER BIRDS}

Rather than being endemic, avian cholera may be a new phenomenon in the arctic nesting Common Eiders, introduced to the population by carrier birds among eiders or alternative host species. Apparently healthy birds are known to carry virulent $P$. multocida (Samuel et al. 1997, 2003a, 2005, 2007). At East Bay, P. multocida serotype 1 was identified as the cause of death in 2005 when avian cholera was first confirmed (Chapter 2). Pasteurella multocida serotype 1 has also been responsible for periodic epizootics among eiders breeding in the St. Lawrence River (Canadian Cooperative Wildlife Health Centre, unpublished data). Among Baltic Common Eiders S. m. mollissima avian cholera mortalities have been observed at the wintering grounds (Christensen et al. 1997, Christensen 2008). East Bay eiders wintering in the St. Lawrence estuary come into contact with individuals from the St. Lawrence River breeding populations (Goudie et al. 2000, Mosbech et al. 2006). Therefore, avian cholera may have entered arctic nesting eider populations on their winter foraging sites.

Alternatively, carriers among alternative host species may have introduced avian cholera to the East Bay eider population. Pasteurella multocida serotype 1 is the primary bacterial strain associated with avian cholera mortality among snow geese (Brogden and 
Rhoades 1983, Samuel et al. 2003b). Snow geese have been suspected to be vectors of the disease (Wobeser et al. 1979, Brand 1984) and mortality of snow geese on their wintering grounds was correlated to mortality among other waterfowl species (Blanchong et al. 2006a). Some snow geese from the central flyway passing through the Rainwater Basin in Central Nebraska, within which avian cholera has been endemic since 1970 (Blanchong et al.2006a), use East Bay Island as a stop-over site on their northward migration about a month prior to the arrival of eiders. As virulent $P$. multocida can survive in the environment for several weeks (Price and Brand 1984, Botzler 1991), it is possible that snow geese may have introduced the pathogen to the East Bay Island Common Eiders.

The importance of gulls as carriers of the disease is unknown. However, gulls feeding on diseased carcasses have been shown to shed virulent bacteria for 120 hours (Samuel et al. 2007). East Bay Island supports a stable breeding population of Herring Gulls Larus argentatus which are migratory and may, therefore, play a role in the spread of avian cholera. Genotypic analysis of bacterial isolates from potential carrier species and geographically separate avian cholera outbreaks may reveal possible links between past and recent outbreaks in Common Eider populations from Maine to the Arctic or, alternatively, between outbreaks on the wintering grounds of migratory waterfowl staging at East Bay Island.

\section{THREAT TO OTHER POPULATIONS}

Since 2006, Common Eider males have been affected by avian cholera at East Bay Island (Chapter 2). Males usually do not return to the same breeding colonies but disperse 
following new mates from the wintering grounds (Swennen 1990, Goudie et al. 2000, Mosbech et al. 2006). Males, which survive avian cholera epizootics at East Bay Island, may become carriers of the disease and spread it to as yet unaffected breeding colonies in the arctic. To evaluate the danger of males spreading avian cholera to new colonies, their ability to become carriers would need to be examined.

\section{CONCLUSION}

Avian cholera has not been reported among arctic nesting Common Eiders prior to 2004, which marked the beginning of annual avian cholera outbreaks at East Bay Island, Nunavut. The reason for the recent emergence of avian cholera among arctic nesting Common Eiders remains unclear; however, the disease has caused a $32 \%$ decline of the breeding population at East Bay with annual mortality remaining high despite the greatly reduced population size. My results suggest, that population density does not play a role in the East Bay avian cholera epizootics, indicating that further population declines can be expected. The severity of mortality within a year appears to be regulated by the duration of the epizootic within a nesting season, and this effect may be enhanced by the observed heightened risk of mortality late in the epizootic. The shift in the bacterial strain from serotype 1 to serotype $3 \times 4$ and the associated variation in mortality rate emphasizes that bacterial strains need to be taken into consideration when interpreting annual and inter-annual disease dynamics. I have also shown that handling stress can increase the probability of death due to avian cholera suggesting that external stressors, such as changing environmental conditions, may have contributed to the emergence of avian cholera among arctic nesting eiders. The results of this thesis can contribute to the 
formulation of predictive models projecting future population trends; and annual and inter-annual trends described within this thesis allow for the testing of the adequacy of different parameter estimates used in lieu of empirical data in predictive models which may provide a guideline for management strategies.

The results of this thesis have also highlighted many gaps in our knowledge of the factors governing the persistence of the disease within populations. In particular, the ability of individuals to develop protective immunity, the role of environmental stressors in affecting mortality, the role of carrier birds and alternative hosts in maintaining and spreading the disease, and the presence of possible links to other bird populations affected by avian cholera need to be elucidated. In order to evaluate the threat of avian cholera spreading to new colonies, the potential of males and of alternative hosts to act as carriers of the disease, as well as their dispersal and migratory routes need to be examined. Knowledge of the importance of these factors in the persistence and spread of avian cholera would greatly improve the reliability of any predictions being made about the future viability of populations affected by this disease. 


\section{LITERATURE CITED}

Anderson, R.M. \& May, R.M. (1979) Population biology of infectious diseases: Part I. Nature 280, pp. 361-367

Anderson, R.M. \& May, R.M. (1978) Regulation and stability of host-parasite population interactions: I. Regulatory processes. Journal of Animal Ecology 47, pp. 219-247

Barber, D.G., Lukovich, J.V., Keogak, J., Baryluk, S., Fortier, L., \& Henry, G.H.R. (2008) The Changing Climate of the Arctic. Arctic 61, pp. 7-26

Begon, M., Bennett, M., Bowers, R.G., French, N.P., Hazel, S.M., \& Turner, J. (2002) A clarification of transmission terms in host-microparasite models: numbers, densities and areas. Epidemiology and Infection 129, pp. 147-153

Blackall, P.J. \& Miflin, J.K. (2000) Identification and typing of Pasteurella multocida: a review. Avian Pathology 29, pp. 271-287

Blanchard, D.C. \& Syzdek, L. (1970) Mechanisms for the water-to-air transfer and the concentration of bacteria. Science 170, pp. 626-628

Blanchong, J.A., Samuel, M.D., \& Mack, G. (2006a) Multi-species patterns of avian cholera mortality in Nebraska's Rainwater Basin. Journal of Wildlife Diseases 42, pp. 8191

Blanchong, J.A., Samuel, M.D., Goldberg, D.R., Shadduck, D.J., \& Lehr, M.A. (2006b) Persistence of Pasteurella multocida in wetlands following avian cholera outbreaks. Journal of Wildlife Diseases 42, pp. 33-39

Bottitta, G.E. (2001) Effects of body condition and environmental variability on incubation behaviour and nest success of arctic-breeding Common Eiders (Somateria mollissima). M.Sc. thesis, Trent University

Bottitta, G.E., Nol, E., \& Gilchrist, H.G. (2003) Effects of experimental manipulation of incubation length on behavior and body mass of Common Eiders in the Canadian Arctic. Waterbirds 26, pp. 100-107

Botzler, R.G. (1991) Epizootiology of avian cholera in wildfowl. Journal of Wildlife Diseases 27, pp. 367-395

Bourgeon, S. \& Raclot, T. (2006) Corticosterone selectively decreases humoral immunity in female eiders during incubation. Journal of Experimental Biology 209, pp. 4957-4965 
Bourgeon, S., Martinez, J., Criscuolo, F., Le Maho, Y., \& Raclot, T. (2006a) Fastinginduced changes of immunological and stress indicators in breeding female eiders. General and Comparative Endocrinology 147, pp. 336-342

Bourgeon, S., Criscuolo, F., Le Maho, Y., \& Raclot, T. (2006b) Phytohemagglutinin response and immunoglobulin index decrease during incubation fasting in female common eiders. Physiological and Biochemical Zoology 79, pp. 793-800

Boyce, J.D., Lo, R.Y.C., Wilkie, I., \& Alder, B. (2004) Pasteurella and Mannheimia. Pathogenesis of bacterial infections in animals $3^{\text {rd }}$ edn. (eds Gyles, C.L., Prescott, J.F., Songer, J.G., \& Thoen, C.O.), pp. 273-294. Blackwell Publishing, Ames, IA

Brand, C.J. (1984) Avian Cholera in the Central and Mississippi Flyways during 19791980. Journal of Wildlife Diseases 48, pp. 399-406

Briggs, K.T., Yoshida, S.H., \& Gershwin, M.E. (1996) The influence of petrochemicals and stress on the immune system of seabirds. Regulatory Toxicology and Pharmacology 23, pp. 145-155

Briggs, K.T., Gershwin, M.E., \& Anderson, D. W. (1997) Consequences of petrochemical ingestion and stress on the immune system of seabirds. Ices Journal of Marine Science 54, pp. 718-725

Brogden, K.A. \& Rhoades, K.R. (1983) Prevalence of serologic types of Pasteurella multocida from 57 species of birds and mammals in the United States. Journal of Wildlife Diseases 19, pp. 315-320

Christensen, T.K., Bregnballe, T., Andersen, T.H., \& Dietz, H.H. (1997) Outbreak of Pasteurellosis among wintering and breeding Common Eiders Somateria mollissima in Denmark. Wildlife Biology 3, pp. 125-128

Christensen, T.K. (2008) Factors affecting population size of Common Eiders Somateria mollissima. PhD thesis, National Environmental Institute, University of Aarhus

Côté, I.M. \& Poulin, R. (1995) Parasitism and group size in social animals - a metaanalysis. Behavioral Ecology 6, pp. 159-165

Coulson, J.C. (1984) The population dynamics of the eider duck Somateria mollissima and evidence of extensive non-breeding by adult ducks. Ibis 126, pp.525-543

Cox, R.R. \& Afton, A.D. (1998) Effects of capture and handling on survival of female Northern Pintails. Journal of Field Ornithology 69, pp. 276-287

Criscuolo, F., Gauthier-Clerc, M., Gabrielsen, G.W., \& Le Maho, Y. (2000) Recess behaviour of the incubating Common Eider Somateria mollissima. Polar Biology 23, pp. $571-574$ 
Gaston, A.J. (2004) Report on surveys and research at Digges Island and vicinity, 27 July - 9 August 2004. Canadian Wildlife Service, Ottawa, ON, pp. 1-15

Gershman,M., Witter, J.F., Spencer, H.E., \& Kalvaitis, A. (1964) Case report: Epizootic of fowl cholera in the Common Eider duck. Journal of Wildlife Management 28, pp. 587589

Gilchrist, H.G. \& Robertson, G.J. (2000) Observations of marine birds and mammals wintering at polynyas and ice edges in the Belcher Islands, Nunavut, Canada. Arctic 53, pp. 61-68

Gilliland, S., Gilchrist, H.G., Rockwell, R.F., Robertson, G.J., Savard, J.P., Merkel, F.R., \& Mosbech A. (2009) Evaluating the harvest of northern Common Eiders in Greenland and Canada. Wildlife Biology, in press

Goltz, J.P. and Bowes, S. (1994) Avian cholera and predation in nesting Common Eiders in New Brunswick. Canadian Cooperative Wildlife Centre Newsletter 1-3

Gordus, A.G. (1993) Notes on the first known avian cholera epizootic in wildfowl in North America. Journal of Wildlife Diseases 29, pp. 367

Goudie, R.I., Robertson, G.J., \& Reed, A. (2000) Common Eider (Somateria mollissima). pp. 1-31. Cornell Laboratory of Ornithology and the Academie of Natural Sciences, Philadelphia, PA

Greene, C.H., Pershing, A.J., Cronin, T.M., \& Ceci, N. (2008) Arctic climate change and its impacts on the ecology of the North Atlantic. Ecology 89, pp. S24-S38

Gulland, F.M.D. (1995) The impact of infectious diseases on wild animal populations - a review. Ecology of Infectious Diseases in Natural Populations (eds Grenfell, B.T. \& Dobson, A.P.), pp. 20-51. Cambridge University Press, New York

Hanssen, S.A., Erikstad, K.E., Johnsen, V., \& Bustnes, J.O. (2003a) Differential investment and costs during avian incubation determined by individual quality: an experimental study of the common eider (Somateria mollissima). Proceedings of the Royal Society of London Series B-Biological Sciences 270, pp. 531-537

Hanssen, S.A., Folstad, I., Erikstad, K.E., \& Oksanen, A. (2003b) Costs of parasites in Common Eiders: effects of antiparasite treatment. Oikos 100, pp. 105-111

Hanssen, S.A., Hasselquist, D., Folstad, I., \& Erikstad, K.E. (2004) Costs of immunity: immune responsiveness reduces survival in a vertebrate. Proceedings of the Royal Society of London Series B-Biological Sciences 271, pp. 925-930

Hanssen, S.A., Hasselquist, D., Folstad, I., \& Erikstad, K.E. (2005) Cost of reproduction in a long-lived bird: incubation effort reduces immune function and future reproduction. 
Proceedings of the Royal Society of London Series B-Biological Sciences 272, pp. 10391046

Hanssen, S.A. (2006) Costs of an immune challenge and terminal investment in a longlived bird. Ecology 87, pp. 2440-2446

Harper, M., Boyce, J.D., \& Adler, B. (2006) Pasteurella multocida pathogenesis: 125 years after Pasteur. Fems Microbiology Letters 265, pp. 1-10

Harwood, J. \& Hall, A. (1990) Mass mortality in marine mammals - its implications for population dynamics and genetics. Trends in Ecology \& Evolution 5, pp. 254-257

Henri, D. (2007) The integration of Inuit traditional ecological knowledge and western science in wildlife management in Nunavut, Canada: The case of avian cholera outbreaks among Common Eider ducks in the West Husdon Strait and North James Bay area. M.Sc. thesis, Oxford University

Hundt, M.J. \& Ruffolo, C.G. (2005) Interaction of Pasteurella multocida with free-living amoebae. Applied and Environmental Microbiology 71, pp. 5458-5464

Kwan, M. (2004) Avian cholera outbreak in Ivujivik. Makivik Magazine 70, pp. 31-32

Lancaster, L.T., Hazard, L.C., Clobert, J., \& Sinervo, B.R. (2008) Corticosterone manipulation reveals differences in hierarchical organization of multidimensional reproductive trade-offs in r-strategist and K-strategist females. Journal of Evolutionary Biology 21, pp. 556-565

Leotta, G.A., Chinen, I., Vigo, G. B., Pecoraro, M., \& Rivas, M. (2006) Outbreaks of avian cholera in Hope Bay, Antarctica Journal of Wildlife Diseases 42, pp. 259-270

Lepage, D., Gauthier, G., \& Menu, S. (2000) Reproductive consequences of egg-laying decisions in snow geese. Journal of Animal Ecology 69, pp. 414-427

Lloyd-Smith, J.O., Cross, P.C., Briggs, C.J., Daugherty, M., Getz, W.M., Latto, J., Sanchez, M.S., Smith, A.B., \& Swei, A. (2005) Should we expect population thresholds for wildlife disease? Trends in Ecology \& Evolution 20, pp. 511-519

Martin II, L.B., Scheuerlein, A., \& Wikelski, M. (2003) Immune activity elevates energy expenditure of house sparrows: a link between direct and indirect costs? Proceedings of the Royal Society of London Series B-Biological Sciences 270, pp. 153-158

Matsumoto, M. \& Strain, J.G. (1993) Pathogenicity of Pasteurella multocida: its variable nature demonstrated by in-vivo passages. Avian Diseases 37, pp. 781-785

McCallum, H. \& Dobson, A. (1995) Detecting disease and parasite threats to endangered species and ecosystems. Trends in Ecology \& Evolution 10, pp. 190-194 
McCallum, H., Barlow, N.D., \& Hone, J. (2001) How should pathogen transmission be modelled? Trends in Ecology \& Evolution 16, pp. 295-300

McEwen, B.S., Biron, C.A., Brunson, K.W., Bulloch, K., Chambers, W.H., Dhabhar, F. S., Goldfarb, R.H., Kitson, R.P., Miller, A.H., Spencer, R.L., \& Weiss, J.M. (1997) The role of adrenocorticoids as modulators of immune function in health and disease: Neural, endocrine and immune interactions. Brain Research Reviews 23, pp. 79-133

McLandress, M.R. (1983) Sex, age, and species differences in disease mortality of Ross' and lesser snow geese in California: Implications for avian cholera research. California Fish and Game 69, pp. 196-206

Merkel, F.R. (2004a) Evidence of population decline in common eiders breeding in Western Greenland. Arctic 57, pp. 27-36

Merkel, F.R. (2004b) Impact of hunting and gillnet fishery on wintering eiders in Nuuk, Southwest Greenland. Waterbirds 27, pp. 469-479

Mosbech A., Gilchrist G., Merkel, F., Sonne C., Flagstad, A., \& Nyegaard H. (2006) Year-round movements of Northern Common Eiders Somateria mollissima borealis breeding in Arctic Canada and West Greenland followed by satellite telemetry. Ardea 94, pp. 651-665

Nelson, R.J., Demas, G.E., Klein, S.L., \& Kriegsfeld, L.J. (2002) Seasonal patterns of stress, immune function, and disease. Cambridge University Press, New York

Otto, S.P. \& Day, T. (2007) A biologist's guide to mathematical modeling in ecology and evolution. Princeton University Press, Princeton, NJ

Owen-Ashley, N.T. \& Wingfield, J.C. (2007) Acute phase responses of passerine birds: characterization and seasonal variation. Journal of Ornithology 148, pp. S583-S591

Parker, H. \& Holm, H. (1990) Patterns of nutrient and energy expenditure in female Common Eiders nesting in the high arctic. $A u k$ 107, pp. $660-668$

Pedersen, K., Dietz, H.H., Jorgensen, J. C., Christensen, T.K., Bregnballe, T., \& Andersen, T.H. (2003) Pasteurella multocida from outbreaks of avian cholera in wild and captive birds in Denmark. Journal of Wildlife Diseases 39, pp. 808-816

Ponjoan, A., Bota, G., De La Morena, E.L.G., Morales, M.B., Wolff, A., Marco, I., \& Manosa, S. (2006) Adverse effects of capture and handling little bustard. Journal of Wildlife Management 72, pp. 315-319

Price, J.I. \& Brand, C.J. (1984) Persistence of Pasteurella multocida in Nebraska wetlands under epizootic conditions. Journal of Wildlife Diseases 20, pp. 90-94 
Råberg, L., Grahn, M., Hasselquist, D., \& Svensson, E. (1998) On the adaptive significance of stress-induced immunosuppression. Proceedings of the Royal Society of London Series B-Biological Sciences 265, pp. 1637-1641

Reed, A. \& Cousineau, J.-G. (1967) Epidemics involving the Common Eider (Somateria mollissima) at Ile Blanche, Québec. Le Naturaliste Canadien 94, pp. 327-334

Rimler, R.B. \& Glisson, J.R. (1997) Fowl cholera. Diseases of Poultry (eds Calnek,B.W., Barnes, H.J., Beard, C.W., McDougald, L.R., \& Saif, Y.M.), pp. 143-159. State University Press, Ames, IA

Robertson, G.J., Reed, A., \& Grant-Gilchrist, H. (2001) Clutch, egg and body size variation among common eiders breeding in Hudson Bay, Canada. Polar Research 20, pp. 85-94

Romero, L.M. \& Romero, R.C. (2002) Corticosterone responses in wild birds: The importance of rapid initial sampling. Condor 104, pp. 129-135

Rosen, M. (1969) Species susceptibility to avian cholera. Bulletin of the Wildlife Disease Association 5, pp. 195-198

Rosen, M. (1971) Avian Cholera. Infectious and parasitic diseases of wild birds (eds Davis, J.W., Anderson, R.C., Karstad, L., \& Trainer, D.O.), pp. 59-74. The Iowa State University Press, Iowa

Ryder, J.J., Miller, M.R., White, A., Knell, R.J., \& Boots, M. (2007) Host-parasite population dynamics under combined frequency- and density-dependent transmission. Oikos 116, pp. 2017-2026

Salvante, K.G. \& Williams, T.D. (2003) Effects of corticosterone on the proportion of breeding females, reproductive output and yolk precursor levels. General and Comparative Endocrinology 130, pp. 205-214

Samuel, M.D., Goldberg, D.R., Shadduck, D.J., Price, J.I., \& Cooch, E.G. (1997) Pasteurella multocida serotype 1 isolated from a lesser snow goose: Evidence of a carrier state. Journal of Wildlife Diseases 33, pp. 332-335

Samuel, M.D., Takekawa, J.Y., Samelius, G., \& Goldberg, D.R. (1999) Avian cholera mortality in lesser snow geese nesting on Banks Island, Northwest Territories. Wildlife Society Bulletin 27, pp. 780-787

Samuel, M.D., Shadduck, D.J., Goldberg, D.R., \& Johnson, W.P. (2003a) Comparison of methods to detect Pasteurella multocida in carrier waterfowl. Journal of Wildlife Diseases 39, pp. 125-135 
Samuel, M.D., Shadduck, D.J., Goldberg, D.R., Wilson, M.A., Joly, D.O., \& Lehr, M.A. (2003b) Characterization of Pasteurella multocida isolates from wetland ecosystems during 1996 to 1999. Journal of Wildlife Diseases 39, pp. 798-807

Samuel, M.D., Shadduck, D.J., \& Goldberg, D.R. (2004) Are wetlands the reservoir for avian cholera? Journal of Wildlife Diseases 40, pp. 377-382

Samuel, M.D., Shadduck, D.J., Goldberg, D.R., \& Johnson, W.P. (2005) Avian cholera in waterfowl: The role of lesser snow and Ross's geese as disease carriers in the Playa Lakes Region. Journal of Wildlife Diseases 41, pp. 48-57

Samuel, M.D., Botzler, R.G., \& Wobeser, G. (2007) Avian Cholera. Infectious diseases of wild birds (eds Thomas, N.J., Hunter, D.B., \& Atkinson, C.T.), pp. 239-269. Blackwell Publishing, Iowa

Sapolsky, R.M., Romero, L.M., \& Munck, A.U. (2000) How do glucocorticoids influence stress responses? Integrating permissive, suppressive, stimulatory, and preparative actions. Endocrine Reviews 21, pp. 55-89

Scott, M.E. (1988) The Impact of Infection and Disease on Animal Populations: Implications for Conservation Biology. Conservation Biology 2, pp. 40-56

Sedinger, J.S., Lindberg, M.S., Rexstad, M.S., Rexstad, E.A., Chelgren, N.D., \& Ward, D.H. (1997) Testing for handling bias in survival estimation for Black Brant. Journal of Wildlife Management 61, pp. 782-791

Sheldon, B.C. \& Verhulst, S. (1996) Ecological immunology: Costly parasite defences and trade-offs in evolutionary ecology. Trends in Ecology \& Evolution 11, pp. 317-321

Silverin, B. (1998) Stress responses in birds. Poultry and Avian Biology Reviews 9, pp. 153-168

Smith, K.F., Sax, D.F., \& Lafferty, K.D. (2006) Evidence for the role of infectious disease in species extinction and endangerment. Conservation Biology 20, pp. 1349-1357

Smith, K.F., Acevedo-Whitehouse, K., \& Pedersen, A.B. (2009) The role of infectious diseases in biological conservation. Animal Conservation 12, pp. 1-12

Svensson, E., Raberg, L., Koch, C., \& Hasselquist, D. (1998) Energetic stress, immunosuppression and the costs of an antibody response. Functional Ecology 12, pp. 912-919

Swennen, C. (1990) Dispersal and migratory movements of eiders Somateria mollissima breeding in the Netherlands. Ornis Scandinavica 21, pp. 17-27

van Oers, K. \& Carere, C. (2007) Long-term effects of repeated handling and bleeding in wild caught Great Tits Parus major. Journal of Ornithology 148, pp. S185-S190 
Wakeley,J.S. \& Mendall, H. L. (1976) Migrational homing and survival of adult female eiders in Maine. Journal of Wildlife Management 40, pp. 15-21

Waller, L.J. \& Underhill, L.G. (2007) Management of avian cholera Pasteurella multocida outbreaks on Dyer Island, South Africa, 2002-2005. African Journal of Marine Science 29, pp. 105-111

Weimerskirch, H. (2004) Diseases threaten southern ocean albatrosses. Polar Biology 27, pp. 379

Wilson, L. \& Gaston, A.J. (2001) Effects of handling stress on Brunnich's Guillemots Uria lomvia. Ringing and Migration 20, pp. 320-327

Wingfield, J.C. \& Farner, D.S. (1993) Endocrinology of reproduction in wild species. Avian Biology (eds. Farner, D.S., King, J.R. \& Parkes, K.C.) pp. 163-327. Academic Press, New York

Wingfield, J.C., O'Reilly, K.M., \& Astheimer, L.B. (1995) Modulation of the adrenocortical responses to acute stress in arctic birds: A possible ecological basis. American Zoologist 35, pp. 285-294

Wingfield, J.C., Maney, D.L., Breuner, C.W., Jacobs, J.D., Lynn, S., Ramenofsky, M., \& Richardson, R.D. (1998) Ecological bases of hormone-behavior interactions: The "emergency life history stage". American Zoologist 38, pp. 191-206

Wobeser, G., Hunter, D.B., Wright, B., Nieman, D.J., \& Isbister, D.J. (1979) Avian cholera in waterfowl in Saskachewan, spring 1977. Journal of Wildlife Diseases 15, pp. 19-24

Wobeser, G. (1992) Avian cholera and waterfowl biology. Journal of Wildlife Diseases 28, pp. 674-682

Wobeser, G. (1997) Diseases of wild waterfowl pp. 57-69. Plenum Press, New York Zar, J.H. (1999) Biostatistical Analysis, 4 edn. Prentice-Hall Canada Inc., Toronto 